Universidad Nacional de La Plata

FACULTAD DE HUMANIDADES Y Ciencias dE LA EdUCACIÓN SECRETARÍA DE Posgrado

\title{
"EL SUJETO CON DERECHO A JUGAR: Entre el juego como derecho y el derecho al juego"
}

Profesora Licenciada: María Julieta Díaz

Tesis para optar por el grado de Magíster en Educación Corporal.

Directora: Mg. María Eugenia Villa, UNLP.

Mar del Plata, 04 de marzo de 2021. 
A mi papá y mi mamá, que me dieron la posibilidad de elegir. 
INTRODUCCIÓN.

> HACIA UNA GENEALOGÍA DEL DERECHO

* Acerca del derecho............................................12

* Acerca de los derechos humanos.............................14

* El derecho, la política y Dios...................................16

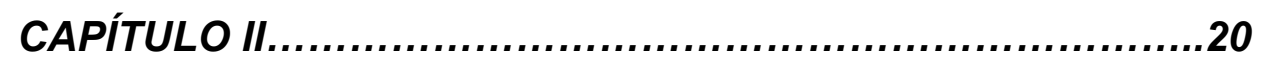

D HACIA EL DERECHO COMO SUJETO JUGADO.........20

* Individuo, portador de derechos............................20

* El derecho en la Grecia antigua..............................22

○ La Demokratía..............................................22

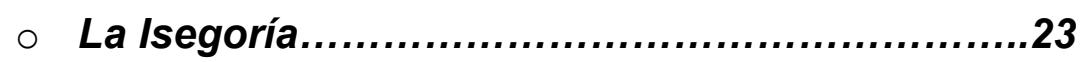

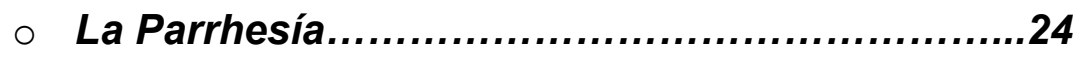

- El individuo como portador de derechos..................26

* Acerca de lo Político..............................................28

* El sujeto DE derechos......................................30

* El juego como necesidad vital..............................31

- Los Diseños Curriculares de la provincia de Buenos Aires.............................................32

○ La necesidad en el juego..............................34

- La vitalidad en el juego..................................40

* Dos caras de una misma moneda, entre la igualdad y la equidad.........................................41

* El derecho como sujeto.....................................42 


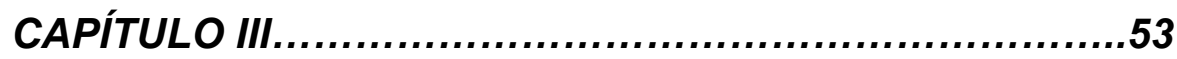

> EL DERECHO COMO DISPOSITIVO DE PODER.....53

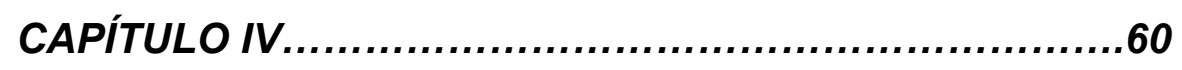

D EL JUEGO COMO PRÁCTICA CORPORAL...........60

* El juego es una acción en tanto acto político.......62

- Características de las prácticas.................66

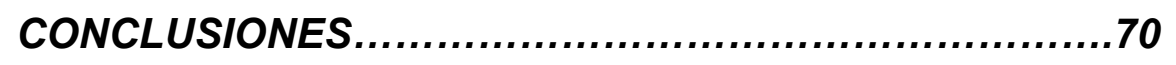

BIBLIOGRAFÍA UTILIZADA...................................75 


\section{AGRADECIMIENTOS}

En el transcurso de todo el tiempo que me llevó realizar y concluir este trabajo de investigación, me he cruzado con compañeros, colegas, amigos y familiares que de alguna manera u otra, me han acompañado en la finalización de la misma y que quisiera agradecer. Sabiendo que ninguna tesis se construye solo, que siempre es con el acompañamiento y ayuda de un Otro.

En principio agradecer a mi familia, mis hijos Marina y Elías, quienes con su inocencia, supieron darme los momentos para poder llevar a cabo este trabajo, y en especial a Juan, mi compañero de vida quien con sus reflexiones diarias me acompañó en esta ardua tarea que comenzó hace más de una década en aquellos viajes mensuales a la ciudad de La Plata, nuestra segunda casa.

En segunda instancia, quiero agradecer a mi directora María Eugenia Villa, (Cuca), quien con su lectura precisa y su paciencia supo guiarme en esta construcción.

Quisiera agradecer a un referente y maestro en todo mi recorrido de formación, Ricardo Crisorio quien con su generosa acción de compartir su saber, me permitió dudar en todo momento

Sumar también en este agradecimiento a los amigos del no-grupo, por sus aportes teóricos, en especial a Víctor Pavía, Adolfo Corbera, Leo Díaz, Dani Devita, Ceci Taladriz, Jorge Nella, Jorge Aldao. A las lecturas y aportes de Ivana Rivero, Agustín Lescano. A la amistad, la escucha y hospedaje de Silvana Simoy.

También quiero agradecer a mis compañeros del grupo de estudio y de trabajo Lore, Caro y Javi, con quienes llegamos a construir una hermosa amistad y que con sus preguntas e inquietudes me permitieron ir formulando este trabajo.

Y si hablo de amistad, agradezco a mis amigas del alma y colegas Eli Catelli, Claudia Longo, Nati Yenni y Marce Harispe quienes más cerca o más lejos, me apoyaron, escucharon y leyeron. 
Simplemente, GRACIAS. 
"Hay un momento en el cual aquello que nos parecía lo más obvio, el mundo, deja de ser tal.

El mundo no ha desaparecido ante nosotros, sigue siendo el mismo que era, en ese sentido no hemos perdido nada.

Salvo la obviedad. Y cuando esta aceptación 'natural' del mundo se transforma, por su propio desfondamiento, no sólo el mundo deja de ser 'obvio', sino que nosotros mismo dejamos de ser en él "algo natural". Es decir, nosotros ya no somos tan obvios para nosotros mismos."

Lo obvio.

Pelayo Pérez.

\section{INTRODUCCIÓN}

El presente trabajo de investigación, comenzó a partir de pensamientos y reflexiones sobre cómo fue constituido el concepto de derecho, y cuáles son las consecuencias actuales de esa idea, en particular la de derecho al juego y al jugar. Situación más que obvia, me decían. ¿Cómo dudar o poner en cuestión los derechos y garantías de los mismos? Es por esto, por la obviedad, que el trabajo de investigación se dirigió por este camino, por el camino de lo obvio, puesto que aquello que creemos tan obvio, no lo es tanto.

Como obvio se designa algo que es evidente o visible. La palabra, como tal, proviene del latín obvius, y se encuentra compuesta de ob-, que indica 'delante de' o 'frente a', y -via, que significa 'camino'. De allí que algunos de los sinónimos de obvio sean: evidente, visible, manifiesto, notorio, patente, claro, fácil y elemental. En este sentido, lo obvio es "lo que se encuentra frente a los ojos", que se puede percibir fácilmente y sin obstáculos. A pesar de todo esto, fueron surgiendo algunos obstáculos, en donde no todo era tan evidente, tan notorio, tan claro y menos tan fácil. 
Este trabajo de investigación, se organiza en cuatro capítulos. Los mismos van realizando un recorrido no sólo histórico sino también genealógico, problematizando las posiciones epistemológicas que en el derecho y el derecho al juego y al jugar han sido vinculadas. En consecuencia, los discursos sobre estas posiciones hegemónicas, ingresan a modo de verdades absolutas en prácticas históricas, sociales y políticas.

En principio, el derecho como toda palabra polisémica, nos invita a pensar que no sólo hay un significado sobre el mismo, y es por este camino que comencé a indagar sobre el concepto. En el capítulo I, se presentan las diversas maneras de pensar el derecho, cuáles fueron los primeros momentos donde fue nombrado para poder hacer uso, ya sea de la palabra o del ejercicio del poder; cuáles fueron los momentos claves para que el derecho se presente en los discursos de la época. Esto conlleva ir construyendo un entramado de manera genealógica sobre el derecho, analizando cuáles son las vinculaciones del saber en términos de estrategia y prácticas de poder. En el recorrido de estas estrategias y prácticas de poder, emergen conceptos claves como lo político, la política y las vinculaciones con Dios, que se desarrollan en este primer capítulo.

Continúa este capítulo, presentando una clasificación del derecho desde diferentes autores que coinciden en la misma como derechos subjetivos, derechos objetivos, y derechos jurídicos, y a partir de la cual cada uno de ellos, responden a cuestiones o bien individuales, o bien colectivos o bien a razones de índole legal.

Esta tesis, trata de establecer precisión en el objeto de estudio, dicho objeto implica dar cuenta que el derecho y como consecuencia el derecho al juego y al jugar, se han constituido y se constituyen desde una posición naturalista, biologicista o bien sustancialista. Esta posición ha ido ingresando en las diferentes instituciones como discursos válidos o hegemónicos y de manera evidente, notoria y clara; lo cual conlleva una manera de pensar el sujeto que juega.

En el capítulo II, se propone indagar sobre cuál es ese sujeto que juega, es decir cuál es la teoría del sujeto que suscribe en el pensamiento del derecho como 
esencial y natural. ¿Es sujeto o es individuo?, ¿cuáles son las diferencias entre estos dos términos? Y si pensamos en sujeto, ¿qué, cuál, cuáles sujeto/s?

Este segundo capítulo, realiza un importante recorrido y análisis sobre teorías que han pensado al sujeto en términos de derecho y que implicancias ha traído a partir de considerarse como "Sujeto portador de derechos", pasando por "Sujeto de derecho", y al finalizar este segundo capítulo se fundamenta y se propone otra mirada del mismo, pensándolo desde el "Derecho como sujeto jugado". Cada uno de estos modos de conceptualizar al sujeto, han sido analizados a partir de problematizar las posiciones epistémicas enmarcadas no sólo en momentos históricos donde se iban forjando las sociedades, sino también en términos de estrategias de saber y prácticas de poder.

Uno de los análisis que plantea esta tesis, es poner en consideración que no se reconoce al derecho del niño como lo propone la Convención de los Derechos del Niño, en el artículo 31: "Los Estados Partes reconocen el derecho del niño al descanso y el esparcimiento, al juego y a las actividades recreativas propias de su edad y a participar libremente en la vida cultural y en las artes." (Unicef: 2006); puesto que delimitarlo en una franja etaria, implica pensar al sujeto que está dentro de él y determinado por él. Más bien, se reconoce un derecho al sujeto jugado, que se constituye en el mismo momento que está jugando.

El presente trabajo se encuentra enmarcado en la teoría de la Educación Corporal, es decir en una manera de pensar el sujeto y por ende de pensar el sujeto de las prácticas, el sujeto de la educación y el sujeto de la ciencia. "La Educación Corporal entiende al cuerpo y al ser humano mismo como constituidos en un orden simbólico" (Crisorio, 2015:167). La Educación Corporal, propone una disciplina en particular, diferente a la Educación Física, plantea como objeto de estudio las Prácticas Corporales, las cuales implican "prácticas históricas, por ende políticas que toman por objeto a las acciones del cuerpo" (2015:170). El objeto de estudio de la Educación Corporal no es a priori, sino que se va construyendo a medida que se lo va investigando; a diferencia de la Educación Física donde el objeto de estudio está dado, el cual sería en este caso, el movimiento humano. 
Las diferencias entre Educación Corporal y Educación Física son muchas ${ }^{1}$, puesto que pensarse en una o en otra, responde al posicionamiento que uno enseñante- pueda enfrentar en la enseñanza de las prácticas de la educación del cuerpo, sea en la escuela, sea en el club, sea en la colonia. Por lo tanto, el sujeto que piensa la Educación Corporal hace referencia a un sujeto lógico, es decir un sujeto producto del discurso, construido a partir del discurso. Es por ello que se problematizan los conceptos de derecho y derecho al juego y al jugar, sin especificación de edad o grupos de edades, ya que no consideramos a un niño o un adolescente que tenga u ob-tenga tal o cual derecho, sino que "simplemente" se revelan sujetos.

En el capítulo III, se realizan dos desplazamientos: por un lado, del "Derecho como sujeto jugado" al "Derecho como dispositivo de poder", puesto que, además de que el derecho es constituido como un elemento natural y esencial en la bios2 de los individuos, implica también un dispositivo de poder en términos foucaultianos. El segundo desplazamiento que se realiza en este capítulo, es pasar del "Derecho como dispositivo de poder, al "Juego como Práctica en tanto corporal". En este apartado ya no se considera al jugar, es decir al jugador o a los jugadores; más bien se considera a un sujeto jugado que se constituye en esa práctica denominada Juego. El Juego, se define en tanto saber valioso, como saber a enseñar. En este mismo capítulo, se proponen algunos indicios sobre cuáles son los elementos que constituyen a la estructura del Juego, tomando a los saberes o elementos propuestos por el $\mathrm{GIJ}^{3}$. Elementos que presentan una articulación no determinista, es decir que una no determina a la otra, sino que su vinculación es en términos covariantes, es decir que una se configura en relación a la otra y viceversa.

\footnotetext{
${ }^{1}$ Para ampliar estas diferencias ver "Educación Corporal: algunos problemas". Jornadas de Cuerpo y Cultura, 2008 UNLP.

${ }^{2}$ En términos filosóficos, el pensador Giorgio Agamben lo dice de ésta manera: los griegos diferenciaban bios y zoe. "Bios hace referencia a la manera de vivir propia de un individuo o de un grupo al estilo que le es propio; zoe, en cambio, al hecho de vivir común a todos los vivientes.

${ }_{3}^{3}$ Grupo de Investigación en Juego. UNLP.
} 
Por último, en el capítulo cuarto se plantea un concepto de Juego, a partir de la idea de acción propuesta por Arendt, distanciado del concepto de trabajo y labor, y relacionando a la acción como un acto político donde se involucra a una red de relaciones vinculados a la función covariante de cada uno de los elementos que la conforman. Por lo tanto, se propone al Juego como saber a enseñar, como saber valioso y se plasman algunos indicios para poder problematizar el juego en términos de enseñanza; es decir qué tendría que tener en cuenta para poder enseñar a problematizar el saber del Juego, en tanto Práctica Corporal vinculado al programa de Investigación Científica (P.I.C), denominado Educación Corporal. 


\section{CAPÍTULO I}

\section{HACIA UNA GENEALOGÍA DEL DERECHO}

En el transcurso del tiempo, el derecho se ha ido conformado desde diversas transformaciones y mutaciones; es decir, ha ido modificando su idea principal y alterando o cambiando su lugar en la historia. En este primer capítulo, trataremos de analizar cómo se ha constituido el derecho en general, y el derecho al juego en particular.

Para poder llevar a cabo este trabajo, se investigará no sólo los hechos históricos en donde el derecho se encuentra enmarcado en puntuales sucesos, sino también desde una mirada genealógica la cual pretende "poder analizar el saber en términos de estrategia y prácticas de poder" (Castro, 2004:146); es decir, analizarlos desde los sentidos socio-históricos y políticos que se le ha dado al término y cómo se ha conformado de esta manera y no de otra. Asimismo, la genealogía da cuenta de la constitución de saberes, discursos, dominios de objetos, etc.; es la búsqueda de ideas hegemónicas y a veces contradictorias que revelan cómo el poder influye en las verdades que se da por sentadas en las sociedades.

Por lo tanto, abordar el trabajo genealógicamente, permite vincular al derecho a partir de la procedencia en las relaciones de poder y a la emergencia en las relaciones de saber.

La tesis busca mostrar que el derecho en general y el derecho al juego en particular, se constituyó y se constituye en vinculación a la naturaleza humana, a lo natural de lo humano. Aun cuando se intentó desplazar la idea de sujeto portador de derechos por la de sujeto de derechos, el juego mantuvo la misma posición en tanto medio o recurso para un fin supuestamente superior. Es en esta posición donde se visibiliza y se confunde el individuo con el sujeto, cuestión a analizar más adelante. Este trabajo pretende, entonces, problematizar y analizar cada una de estas perspectivas: sujeto portador de derechos - sujeto de derechos y proponer otra en vinculación al derecho y al juego a partir de la teoría de la 
Educación Corporal, teoría en que se apoya esta tesis. En la misma, no hay naturaleza humana ni derecho alojado en lo natural, más bien hay sujetos que se van constituyendo a partir de lo que representan para otro significante.

\section{- Acerca del derecho}

La palabra "derecho" desde su etimología, deriva de la voz latina "directus", que significa lo derecho, lo recto, lo rígido. Sin embargo, para mencionar la realidad que nosotros llamamos derecho, los romanos empleaban la voz "ius".(DJ.,2014), que en latín hace referencia al derecho objetivo. En la Antigua Roma el ius se le entendía o atribuía al conjunto o grupo de principios y normas equitativas y buenas por los hombres; pero, como toda palabra, el derecho no se escapa de su condición polisémica, aunque de acuerdo a las reglamentaciones jurídicas, la palabra derecho puede tomarse desde tres acepciones distintas: Derecho objetivo, Derecho subjetivo y Derecho equivalente a justicia.

La primera acepción, designa el conjunto de normas o reglas que rigen la actividad humana en la sociedad, cuya inobservancia es sancionada por el poder público: el Derecho objetivo. La segunda, designa las facultades pertenecientes al individuo, un poder del individuo que le permite gozar de algo o de un valor, o exigir de otro una prestación: el Derecho subjetivo. En tercer lugar, el derecho como equivalente a justicia, como portador del valor justicia, denominado derecho jurídico.

El objetivo de la reglamentación de las normas jurídicas es el comportamiento humano. Pero no es el derecho el único conjunto de normas que regulan la vida del hombre, junto a él existen reglas morales y éticas que pretenden igualmente dirigir las relaciones del hombre en sociedad.

Para definir el derecho desde el punto de vista jurídico recurrimos, en principio, a dos autores de finales del siglo XIX como Léon Duguit (Libourne, 1859 - Burdeos, 1928), jurista francés y a Icilio Vanni (Roma 1855-1903) filósofo y sociólogo italiano. Duguit propuso que el derecho "es una regla de conducta impuesta a los individuos que viven en sociedad, regla cuyo respeto se considera, por una sociedad y en un momento dado, como la garantía del interés común, cuya violación produce contra el autor de dicha violación una reacción colectiva". 
(Duguit, L). Por su parte Vanni plantea que "el derecho, en sentido objetivo, es el conjunto de las normas generales impuestas a la acción humana en sus relaciones externas y apoyadas por la autoridad del estado, para garantizar la realización de los fines del individuo y de la comunidad".

Ambas definiciones le otorgan a la palabra derecho, argumentos jurídicos, legales e individuales en donde hay una o varias leyes las cuales cumplir, responder, obedecer puesto que son impuestas. En términos de Schmitt, el derecho se origina cuando hay una infracción. "Un proceso, en cuanto acto jurídico, es posible en absoluto recién cuando un derecho resulta negado." (1963: 6)

Con relación a la Convención de los Derechos de los niños y niñas, la misma fue escrita y aprobada el día 20 de noviembre de 1989 para que los gobiernos garanticen y cumplimenten sus derechos, derechos que han sido originados puesto que en algún momento fueron desatendidos por desconocimiento de las sociedades, ya sea por la idea de hombre, por ende de niño que se pensaba constituir. La Convención sobre los Derechos del Niño se convirtió en ley en 1990, después de ser firmada y aceptada por 20 países. Hoy, la Convención ya ha sido aceptada por todos los países del mundo, excepto Estados Unidos.

Muchos son los ejemplos que podríamos observar con relación a la no garantía de derechos de niños y niñas en el mundo, un ejemplo de ello puede señalarse respecto del mercado cafetero globalizado de Nicaragua quien invisibiliza la garantía de los derechos de los niñas y niños, en este caso al trabajo infantil. A partir del 10 de Diciembre de 1948 con la Declaración Universal de los Derechos del Hombre por la asamblea general de la ONU (Organización de las Naciones Unidas), dichos derechos han adquirido carácter relevante e inviolable, tanto dentro de los círculos académicos, como fuera de ellos; son reclamados no solo en foros internacionales, sino también por los movimientos de resistencia de clases y minorías excluidas, e incluso en ámbitos de la vida familiar y cotidiana.

Si bien este conjunto de derechos han sido reconocidos por la sociedad de manera ética, jurídica e internacional, los mismos no han tenido gran impacto en la realidad. Los fenómenos de fragmentación social y cultural, generan 
manifestaciones de diferente índole, debido a la migración de personas que viven en naciones desfavorecidas a zonas económicamente atractivas, todo ello propiciado por la globalización, el libre mercado y el neoliberalismo. En otras palabras, quedan escindidos los derechos civiles y políticos reconocidos formalmente y los derechos sociales, económicos y culturales, como contrapartida de la globalización.

Si derecho se designa a las leyes vigentes y a los métodos legislativos correspondientes, entonces "no significa otra cosa que la legitimación de un determinado status quo en cuyo mantenimiento están lógicamente interesados todos aquellos cuyo poder político o ventaja económica poseen su estabilidad en el seno de ese derecho" (Schmitt, 1993: 92); por lo tanto al habilitar legalmente un status quo, se justifica un derecho superior o "natural" donde los hombres pueden tener un "ordenamiento superior" sobre otros de un "ordenamiento inferior". Es decir que la idea de derecho tal cual la conocemos, ha sido originada no sólo por una indudable transgresión hacia una clase social o grupo social, sino también a partir de relaciones de poder entre un orden superior que domina, legaliza y somete, y uno inferior que por ende resultan dominados, responden y acatan. Es por esto que -como señalamos anteriormente- la constitución de saberes, discursos y dominios de objetos, corresponde a la búsqueda de ideas hegemónicas y a veces contradictorias. Estas ideas, no son posibles de situar en un único momento temporal, es decir, una no es continuación ni principio de la otra, sino que se van con-formando según las relaciones de poder y de saber. Estas relaciones carecen de propiedades lineales, por lo que nos centramos en comprender cuáles y cómo los problemas políticos, determinan problemáticas históricas y no a la inversa.

\section{- Acerca de los derechos humanos}

Cada una de las siguientes problemáticas selladas históricamente, han sido la base de futuros documentos y declaraciones de los derechos humanos. Aunque las atrocidades cometidas en la II Guerra Mundial han marcado, de alguna manera, el nacimiento de la idea de estos derechos. 
En la "Conquista de Babilonia" (539 a.C), cuando Ciro el Grande, el primer rey de la Persia antigua conquista la ciudad de Babilonia, deja en esa situación que todos los esclavos se fueran en libertad, declarando que todas las personas tenían el derecho a escoger su propia religión, estableciendo así la igualdad racial. Pero sus siguientes acciones fueron las que marcaron un avance significativo para la humanidad. Éstos y otros decretos fueron grabados en un cilindro de barro cocido, en lenguaje acadio con escritura cuneiforme, conocido hoy como el Cilindro de Ciro. Este documento antiguo ha sido reconocido en la actualidad como el primer documento de los derechos humanos en el mundo. Está traducido en los seis idiomas oficiales de las Naciones Unidas y sus disposiciones son análogas a los primeros cuatro artículos de la Declaración Universal de los Derechos Humanos.

Desde Babilonia, la idea de los derechos humanos se difundió rápidamente por la India, Grecia y por último a Roma. Ahí nació el concepto de "ley natural", en la observación del hecho de que las personas tendían a seguir, en el transcurso de la vida, ciertas leyes que no estaban escritas y la ley romana se basaba en ideas racionales derivadas de la naturaleza de las cosas.

Otros documentos que afirman los derechos individuales, son la Carta Magna (1215) donde el rey de Inglaterra firma el primer documento que reconoce los derechos de las personas; la Petición del Derecho (1628), un importante documento constitucional inglés que contiene restricciones sobre impuestos no establecidos por el parlamento; la declaración de la Independencia de América (1776), donde se incluye el concepto de los derechos naturales y recoge que todos los seres humanos son iguales y tienen derechos inalienables como el derecho a la vida y a la libertad. También, la Declaración Francesa de los Derechos del Hombre y de los Ciudadanos, producto de la Revolución Francesa (1789), donde se amplían los derechos establecidos en la declaración de la independencia de América y donde se hace hincapié en que tales derechos son naturales. Es aquí donde se manifiesta concretamente el derecho como algo natural, como esencial y propio del ser humano, que esta tesis se propone analizar. De esta manera, la idea de los derechos humanos se extiende por Europa, y a pesar de ello, más allá de este continente los pueblos son colonizados y sus derechos humanos, vulnerados. A través de las protestas pacíficas de 
Mahatma Gandhi (1915), se comienza a difundir que todas las personas del mundo tienen derechos, no solamente en Europa. En la Carta Fundacional de las Naciones Unidas (1945) aparece por primera vez, el término "derechos humanos"; y como consecuencia en (1948), la Declaración Universal de los Derechos Humanos, fue proclamada en la Asamblea de la ONU en París, por primera vez, donde se establecen los derechos humanos fundamentales que deben protegerse en todo el mundo. La DUDH, vuelve a retomar esta idea pues considera a los mismos como naturales, fundamentales, esenciales, cuando en definitiva son ni más ni menos que una propuesta política a una problemática globalizada.

Durante el siglo XXI, a pesar de que todos los países se han adscrito a la Declaración Universal, ésta no cuenta con el peso de la ley, y millones de personas se ven negadas en sus derechos básicos. Por ejemplo, la esclavitud sigue estando presente, millones de personas son perseguidas y discriminadas por motivos de etnia o religión y 10 millones de personas no tienen una nacionalidad, lo que les priva a su vez de gran parte de los derechos más básicos como el de la educación, la salud, la igualdad y la equidad social.

\section{- El derecho, la política y Dios}

El uso del derecho en el siglo XVII, tenía relación por un lado, con la posibilidad de realizar un discurso político, y por otro, que ese discurso se asociaba con disputas teológicas, ya que de esta manera "alimentaban la vida social y política" (Fernández, 1989:97), porque sabían que no podían ser escuchados por muchos si no hablaban con el lenguaje atribuido a Dios y a sus profetas.

Esta relación religioso-política, se encontraba presente en cada una de las acciones sociales:

"la clase media inglesa era alfabetizada, para que pudiera leer la Biblia, en escuelas fundadas por comerciantes que procuraban evitar así el control clerical de la enseñanza; a la interpretación de la Escritura se aplicaban el interés y los intereses de reyes y parlamentarios, de científicos como Bacon, Gassendi y Newton, de 
escritores como Milton o como sir Thomas Browne y, naturalmente, de filósofos como Hobbes y Spinoza." (Fernández, 1989:97)

Por su parte, Spinoza en "El Éxodo" ofrece una teoría bien determinada hacia el poder político quien establece que "esta transferencia del derecho a Dios se llevó a cabo de la misma manera como hemos concebido que se da en toda sociedad, cuando los hombres deciden ceder su derecho natural", y en ese momento los hebreos cedieron sus derechos diciendo "lo que diga Dios, eso haremos". (TTP ${ }^{4}$, XVII, 206).

Tal como se ha pensado el derecho hasta ahora, observamos que, por su parte, el origen del universo también se lo piensa como una razón divina, en la cual "toda historia de la ciencia ha consistido en una comprensión gradual de que los hechos no ocurren de una forma arbitraria, sino que reflejan un cierto orden subyacente, el cual puede estar o no divinamente inspirado" (Hawking, 2013), por lo que podríamos hacer una analogía con el origen del derecho puesto que también ha sido manifestado como divino/natural. Es decir, por un lado, se observan manifestaciones concretas de la obtención de un derecho en términos naturales, y por otro se ceden los derechos en términos de fe.

De esta manera, el poder político concentra en sí todo el derecho natural del que todos los individuos quedan privados-, y este es fuente de todo derecho. Spinoza entiende como derecho natural a,

"las mismas leyes o reglas de la naturaleza conforme a las cuales se hacen todas las cosas, es decir, el mismo poder de la naturaleza. De ahí que el derecho natural de toda la naturaleza y, por lo mismo, de cada individuo se extiende hasta donde llega su poder" (1986:85)

Por lo tanto, "las declaraciones que depositan en la mera existencia humana la posesión de derechos muestran que es en la naturaleza humana y no en las condiciones sociales, económicas, políticas o históricas, que éstos se fundamentan" (Seré, 2017:68). Se considera entonces, un corrimiento de la idea

\footnotetext{
${ }^{4}$ TTP: Tratado Teológico Político
} 
de derecho desde las posturas más teológicas a las posiciones jurídicas-políticas, y desde allí, a la naturaleza humana.

En correlación a lo propuesto por Spinoza sobre el poder político, podríamos argumentar que el Humanismo ha plantado su posición fuertemente, con respecto al derecho y su ejercicio. Etimológicamente, el Humanismo proviene del latín humanitas, humanidad, naturaleza; o bien de humanus, lo que concierne al hombre. Por su parte Edgardo Castro explicita el concepto de Humanismo a partir del Vocabulario de Michel Foucault,

"Yo entiendo por humanismo el conjunto de discursos por medio de los cuales se ha dicho al hombre occidental: 'Aunque tú no ejerzas el poder, a pesar de ello, tú puedes ser soberano. Mejor: cuanto más renuncies a ejercer el poder y mejor estés sometido a quien te lo impone, más serás soberano.' El humanismo es el que ha inventado, alternativamente, estas soberanías sujetadas que son el alma (soberana sobre el cuerpo, sometida a Dios), la conciencia (soberana en el orden del juicio, sometida al orden de la verdad), el individuo (soberano titular de sus derechos, sometido a las leyes de la naturaleza o a las reglas de la sociedad), la libertad fundamental (interiormente soberana, exteriormente consintiente y acordada con su destino). En síntesis, el humanismo es todo esto por medio de lo cual en Occidente se ha bloqueado el deseo de poder, se ha prohibido querer el poder, se ha excluido la posibilidad de tomarlo". (2004:174)

Si nos detenemos en este punto: "el individuo (soberano titular de sus derechos, sometido a las leyes de la naturaleza o a las reglas de la sociedad)", observamos que el humanismo ha tenido cierto grado de compromiso al pensarse a partir del individuo, como así también su asociación a las diferentes concepciones o definiciones sobre el derecho. Es decir, el Humanismo como movimiento intelectual europeo, ha evidenciado y exaltado con sus aportes, las cualidades propias de la naturaleza humana, llevando consigo un posicionamiento sobre la idea de individuo y consecuentemente, sobre la idea de derecho. De esta 
manera, seguimos afirmando la posición en la que se sustenta el derecho en tanto vinculado directamente a la naturaleza del hombre.

En el siguiente capítulo ahondaremos sobre este concepto, sobre cómo la idea de individuo per se se introduce en los documentos y leyes siendo el mismo un portador de derechos, pasando luego por un sujeto de derechos -al juego y al jugar- y finalizando con una propuesta denominada el Derecho como sujeto jugado. 


\section{CAPÍTULO II}

\section{HACIA EL DERECHO COMO SUJETO JUGADO}

Como ya se adelantó en la finalización del capítulo anterior, en este apartado analizaremos cómo fue transformando y mutando la idea de individuo, a la de sujeto; y en consecuencia la modificación hacia un posicionamiento del individuo portador de derechos, pasando por un sujeto de derechos y finalizando en uno de los puntos a proponer en esta tesis, el Derecho como sujeto jugado.

\section{- Individuo, portador de derechos}

El concepto de individuo proviene del latín individuus, 'indivisible', derivado de dividuus 'divisible', se refiere a lo que no puede ser dividido. Las primicias de su aparición en una escala social significativa pueden encontrarse en el mosaico italiano del Trecento o del Quattrocento en el que el comercio y los bancos juegan un papel económico muy importante, donde el comerciante es el prototipo del individuo moderno. "La precariedad del poder político en los Estados italianos lleva al príncipe a desarrollar un espíritu de cálculo, de insensibilidad, de ambición, de voluntarismo que sirve para anteponer su individualidad ante todo". (Le Breton, 1995)

Del derecho romano viene la herencia de la noción de persona como individuo, portador de derechos, puesto que

\footnotetext{
"la relación que la concepción jurídica moderna estableció desde hace tiempo entre la categoría de persona y la de sujeto de derecho, de una manera que hace del primer término condición de pensabilidad del segundo, y viceversa: para reivindicar los así denominados «derechos subjetivos» - a la vida, al bienestar, a la
} 
dignidad-es preciso haber ingresado preventivamente al recinto de la persona, así como, a la inversa, ser persona significa gozar de por sí de esos derechos" (Espósito, 2007:11).

Continúa Espósito, parafraseando a S. Benhabib, que "el derecho a tener derechos significa hoy reconocer a todo ser humano el status universal de persona, con independencia de su ciudadanía nacional”. (2007:12)

Esta tesis, propone la idea de sujeto, puesto que está dividido; y se contrapone a la noción de individuo, persona, ciudadano y ser humano. El sujeto es "producto de una articulación significante, como una novedad, por completo distinta del individuo, la persona, el hombre". (Crisorio, 2019:9)

\begin{abstract}
"En la teoría de Lacan, el concepto de sujeto no coincide ni con individuo (biológico), ni con persona (social e histórica), ni con ciudadano (legal y político), ni con socio (colectivo); (...), sino que aquél es planteado por Lacan como parlêtre -neologismo creado para rechazar el ser del "ser humano" y que se debería traducir: hablanser y no, justamente, "ser hablante" (Eidelsztein,2012:4)
\end{abstract}

El sujeto que propone esta tesis es un sujeto "incontinuo, inconsistente, inconsciente, insistente. No hay un sujeto completo que se puede medir y cuantificar, no hay un sujeto autónomo, ni un sujeto con derechos originarios, ni un sujeto adulto mayor, ni un sujeto practicante;(...), más bien, en una relación de lugares y acciones que de ninguna manera éstos son causados o constituidos por el cuerpo biológico, ni están alojados en las personas o en los individuos o en el movimiento" (Lescano, 2015:10) (las cursivas son nuestras).

Su etimología remite al subjectum latino, traducción del hypokeimenon griego, es decir, "lo que subyace y está en la base. Lo que yace delante". Crisorio entiende que "el sujeto es equiparable al "asunto o materia de que se trata". Por tanto, sujeto implica ya una relación, un "al menos dos", sin que por ello haya dos sujetos. La función creadora, fundadora, del símbolo, se muestra precisamente en 
la palabra, en la medida en que ella establece y funda una relación que no toma a dos sujetos tal como son para juntarlos, sino que los constituye como sujetos en la relación misma que los hace acceder a una dimensión nueva (cf. Lacan, 2009: 5960)". (2019:9)

Desde el punto de vista político, se asume la condición de ciudadano, portador de demandas sociales que lo insertan en el universo del poder y de las leyes, aunque en la Grecia antigua podría ser ciudadano sólo aquel que pertenecía a un demo, y debería tener ciertas condiciones.

\section{- El derecho en la Grecia antigua}

En la Grecia del 200 a. C. el derecho se constituía en la ciudad de los aqueos. Aquí se remontará a Polibio ${ }^{5}$, a quien Foucault (2014:87) hace referencia para definir su régimen político. El mismo lo organiza desde tres grandes perspectivas: la demokratía; la isegoría y la parrhesía. Estas tres características organizan, de alguna manera, la estructura política y social de la época, siglo IV a.C.

\section{- La Demokratía}

La primera, demokratía (la democracia), la define como la participación, no de todos, sino de todos los demos, es decir aquellos que presentan la condición de ciudadano y por ende de miembros del demo (pueblo).

Demokratía: 'gobierno por el pueblo', de demo (el pueblo, tierra; del indoeuropeo da-mo: 'división (de la sociedad), ya que una comunidad se agrupaba en divisiones según la ubicación, de da- 'dividir'+ kratía 'gobierno, autoridad', de krátos 'fuerza, poder'. (DLE).

La democracia, plantea Foucault, se caracteriza por su existencia a partir de ser parte de un nomos, esto es "el hecho de que la regla del juego político y del

\footnotetext{
${ }^{5}$ Polibio (Megalópolis, Grecia, 200 a. C.-118 a. C.) fue un historiador griego, que jugó un papel preponderante en la concepción de lo político dentro del pensamiento griego.
} 
ejercicio del poder se dan el marco de algo que es ley". (2014:162). Otra característica de la democracia, otro rasgo es la isonomía, es decir, en ese marco de ley, prevalece una igualdad ante todos. Esta característica de democracia se retomará más adelante.

Para continuar analizando la idea de democracia, consideramos a otros autores como Schmitt, quien plantea que es la "identidad de dominadores y dominados, gobernantes y gobernados, de los que mandan y de los que obedecen" (2006: 230). Y continúa afirmando que,

"toda democracia verdadera se apoya en que no solamente lo igual se trata igual, sino que lo desigual se trata desigualmente [...]. A la democracia pertenece necesariamente en primer lugar la homogeneidad y en segundo, en caso necesario, la separación o eliminación de lo heterogéneo».

En este sentido, Schmitt retoma la conceptualización etimológica de la democracia: del indoeuropeo da-mo: 'división (de la sociedad), puesto que una comunidad se agrupaba en divisiones según la ubicación en la que se encontraba socialmente. Aunque, como veremos más adelante, una de las características de la parrhesía es la organización de un status social y político de algunos individuos dentro de esa ciudad. O sea que, pensar en términos de democracia, es pensar en términos de divisiones: divisiones de estructuras sociales por ende, de estructuras políticas, divisiones de clases, de status, de espacios en una misma ciudad. Pero sea cual fuere, el lugar donde se situaba cada demos dentro de una comunidad (demo), aparece la isegoría como organización social en igualdad de oportunidades.

\section{○ La Isegoría}

Se la define como la estructura de igualdad en donde hacen que deber y derecho, libertad y obligación, sean lo mismo y que también forme parte del demos, 
"la isegoría, o sea en el sentido etimológico del término, la igualdad de palabra, la posibilidad que tiene todo individuo, con tal de formar parte, desde luego, del demos, de formar parte de los ciudadanos, de disfrutar del acceso a la palabra (...) la isegoría es por último el derecho a tomar la palabra, emitir opinión en el transcurso de una discusión, un debate." (Foucault, 1983).

La isegoría, no sólo tiene como característica formar parte del demos, de cumplir el rol de ciudadano por poseer tierras, etc. sino también, de poder disfrutar del acceso a la palabra la cual puede entenderse en dos sentidos: por un lado, la palabra judicial donde un ciudadano puede defenderse frente a un tribunal; y por el otro, simplemente el derecho a dar su opinión, a discutir y a debatir.

Como veremos en el siguiente apartado, la parrhesía es el decir veraz. Foucault se pregunta cuál sería entonces la diferencia entre isegoría y parrhesía. La gran diferencia entre una y otra, es que en la primera uno tiene derecho a la palabra a dar una opinión sobre alguna situación que acontecía en el demos; en cambio la segunda amplía esta estructura, ya que además de poder dar una opinión y debatir, podía ejercer ese poder. Con la parrhesía podrías tener la "libertad de tomar la palabra y, en la palabra, ejercer el hablar franco", el decir veraz.

En definitiva, la posibilidad de ejercer o no los derechos en el demo, se adquieren mediante un status, mediante una posición social $y$, por consiguiente con el ejercicio de esos derechos que determinan poder que sólo lo obtienen los ciudadanos, los demos. Ese ejercicio de la libertad de la palabra es denominado, según Polibio, como parrhesía.

\section{- La Parrhesía}

Se entiende como la libertad que gozan esos ciudadanos que forman parte del demos de tomar la palabra en el campo de la política, es decir, la posesión del derecho a la palabra en la asamblea. Pero ¿quiénes tenían derecho a esa palabra?, ¿quiénes eran los que gozaban de ese beneficio? Era un ciudadano 
perteneciente a cierta élite. Era quien también debía poseer tierras y sostenerse a dos requisitos fundamentales: por un lado, ese derecho a hablar, esa parrhesía, se transmitía por la línea materna; y por el otro, no debía ser extranjero. Aquí encontramos otro elemento fundamental, para poder tener derecho, en este caso, a la palabra. Ese derecho tenía que ver con la naturaleza de lo humano, quien debía tener la transmisión de sangre desde la línea materna para poder ejercer ese derecho. Ambas: la línea materna y el no ser extranjero, manifestaban sendas restricciones sobre el derecho al habla y sobre la libertad del discurso político.

A su vez, el concepto de parrhesía, se relaciona con dos cuestiones: "por una parte, cierta estructura política que caracteriza a la ciudad, y en segundo lugar, el status social y político de algunos individuos dentro de esa ciudad". (Foucault:1983). Por lo tanto, la parrhesía estaba estrechamente ligada al derecho a la palabra y, en consecuencia, al poder que ese derecho sostenía, lo cual estaba vinculado directamente al status social; es decir se conformaba de esta manera y en tres partes iguales: derecho-poder-status. La parrhesía es un rasgo de la democracia. Sin democracia no hay parrhesía y sin parrhesía no hay democracia, señalaba Polibio.

Por consiguiente, la parrhesía se diferencia en tres categorías:

- La parrhesía política, está ligada al nacimiento, es el famoso privilegio estatutario. Aquí se podía ejercer el poder, el decir veraz.

- La parrhesía judicial, está ligada a una situación de injusticia, pero en este sentido no era para guiar a los ciudadanos, sino más bien ejercía cierto poder sobre ellos.

- La parrhesía moral, está ligada a la confesión, a poder decir el sentimiento sobre las faltas que se cometían a quien pueda guiarlos.

Por otro lado, podríamos definir que la parrhesía también contiene dos fines técnicos: en primer lugar,

"en la literatura epicúrea, expresa una cualidad del fisiólogo (el médico conocedor de la naturaleza) (...). En el segundo lugar, en el contexto más amplio de la relación maestro-discípulo, la parrhesía 
define la actitud del maestro que corresponde al silencio del discípulo". (Castro. 2004: 256)

En ambas acepciones, se consideran determinadas consonancias dado que, de alguna u otra manera, el ejercicio del poder -ya sea del maestro, ya sea del ciudadano-, era de poseer potestad para hacer uso de la palabra silenciando a otros de acuerdo al status jerárquico y/o social que lo situaba en una posición teniendo derecho o no a la palabra, a su uso y al ejercicio del mismo.

En definitiva, estas tres perspectivas: el uso del derecho a hablar, a tomar la palabra, a ejercerla con poder dan cuenta sobre quién o quiénes tenían el beneficio de ese derecho y cómo y dónde podían llevarlo a cabo. Esto iba a depender, según Polibio, del status en tanto posesión de tierras, en tanto línea materna, que lo ubicaba en el demos con cierto poder para poder ejercer la palabra, el decir veraz.

Por lo tanto, la parrhesía implica hacer uso de la palabra de un modo particular, puesto que su uso trae como consecuencia, el ejercicio del poder. Sea cual fuera el uso de la palabra para el ejercicio del poder, ese uso va a depender de cuestiones en principio, naturales, esenciales y propias del ser humano.

\section{- El individuo como portador de derechos}

Retomando el análisis del individuo como portador de derechos, y haciendo un salto en la historia de la civilización, se observa que las diversas distribuciones de los espacios no quedan ajenas al proceso de individualización del momento. $O$ bien como lo propone Schmitt, citado por Cavalletti (2010: 7) en donde "no existen ideas políticas sin un espacio al cual sean referibles, ni espacios o principios espaciales, a los que no correspondan ideas políticas".

En relación a esta cita, podemos pensar en varios ejemplos: en los hospitales donde se aíslan los contagiosos en camas separadas; y poco a poco se tiende a individualizar los cuerpos, las enfermedades, los síntomas, las vidas y las muertes. Las fábricas, que surgen a fines del siglo XVIII, se rigen por el principio 
de la división en zonas individualizantes. Se trata, a la vez, de distribuir a los individuos en un espacio en el que es posible aislarlos y localizarlos, además de controlarlos, por lo que ningún espacio es neutral en términos políticos. Por su parte, la institución escuela, se suma a esta distribución política-espacial: bancos individuales ordenados y organizados hacia adelante, mirando al pizarrón o al maestro. Se observan otras características tales como hileras de alumnos en la clase y en los pasillos; además del alineamiento de los grupos de edad y de género unos a continuación de los otros. En este conjunto de alineamientos obligatorios, cada alumno de acuerdo con su edad, sus adelantos y sus conductas, ocupan ya un orden, un lugar en el cual es el "movimiento perpetuo en el que los individuos sustituyen unos a otros, en un espacio ritmado por intervalos alineados". (Foucault, 150)

La organización de un espacio social fue una de las grandes mutaciones técnicas de la enseñanza tradicional. Al asignar lugares individuales, ha hecho posible el control de cada cual y el trabajo simultáneo de todos, y de esta manera ha organizado una nueva economía del tiempo de un -supuesto- aprendizaje.

Por lo tanto, al haber un espacio organizado, que no es neutral y que por ende, es político, también será un espacio vinculado a las relaciones de poder. Parafraseando a Michel Foucault, escribió en "L'ceil du pouvoir" (1976) la necesidad de "escribir toda una historia de los espacios, que sería al mismo tiempo una historia de los poderes".

Norbert Elías, presenta al individuo a partir de que cada uno es en su interior algo que no puede salir al "exterior", y que ese "interior", lo "propio" de la persona, es su "núcleo" y su "esencia", o en palabras del autor

\footnotetext{
"La idea del individuo aislado, de que es un homo clausus, un mundo cerrado en sí mismo que en último término existe en completa independencia del ancho mundo exterior, determina la imagen del hombre en general. Todos los demás individuos se nos presentan también como homo clausus y su núcleo, su esencia, su auténtico yo se manifiesta, en todo caso, como algo que está cerrado en su
} 
interior, aislado del mundo exterior y de los demás seres humanos por medio de un muro invisible". (2012:58)

Plantea que la teoría del proceso de la civilización permite reconocer que este tipo de vivencia de la individualización es en sí misma algo producido, parte de un proceso social. Pero, en contra de esa teoría se alza con todo su ímpetu el sentimiento personal de existir en ese interior completamente para sí, independiente de los demás seres humanos.

Estos estratos de la vivencia hacen muy fuerte la propensión de construir la sociedad humana a partir de uno mismo, desde el "individuo" en cuanto ser singular, fundado totalmente en sí. La representación del individuo totalmente independiente de la persona singular absolutamente autónoma, constituye el elemento nuclear de una ideología burguesa que ocupa un lugar muy concreto en el abanico de los credos sociales y políticos contemporáneos. $\mathrm{Y}$ como todo posicionamiento es político, nos encontramos con un término que creemos importante aclarar, puesto que el derecho y lo político están asociados uno con el otro.

\section{- Acerca de lo Político}

La asociación de lo político en relación con el derecho implica constituir en la sociedad un ámbito de libertad e igualdad general, configurando de esta manera, una sociedad determinada. Por lo tanto, lo político representa una decisión concreta que se orienta hacia la revisión del derecho vigente. Es por ello, que la representación de un ciudadano en relación a lo político, a la democracia y al derecho no son ingenuos.

"La política aparece como la vía necesaria para modificar el derecho vigente y ajustarlo a las necesidades o intereses actuales de los ciudadanos, o, en su caso, como la posibilidad de desarrollar las garantías que recoge la Constitución." (Schmitt, 1991:24) 
Mendel, por su parte, plantea la concepción de lo político desde los conflictos entre las clases sociales en tanto niveles jerárquicos de cada institución; es decir que la idea de cultura, de ideología, de relaciones sociales es determinada por la clase social, por el trabajo, por los deseos, por la posesión o carencia de poder. A diferencia de la política, que es el uso que lo político hace con relación al ejercicio del poder.

Realizando una analogía, desde este punto de vista, observamos que la isegoría propuesta por Polibio, se asocia con "lo político" propuesto por Mendel; y de la misma manera, la parrhesía se asocia con "la política". Puesto que tanto la isegoría como "lo político", hacen referencia a la organización de una estructura social democrática a partir de las diferencias de status, de clases sociales $\mathrm{y}$, por ende, de una organización jerárquica y lineal. Por su parte, la parrhesía y "la política" ambas, hacen uso de la palabra, en tanto uso y ejercicio del poder.

Si bien se articulan algunas ideas en relación con la isegoría y la parrhesía en correspondencia con lo político y la política, también podemos subrayar algunas diferencias. Por ejemplo en el demo, sólo tenían poder, uso y ejercicio de la palabra aquellos que poseían tierras y el mismo era transmitido por línea materna, no obstante la idea de lo político que plantea Mendel se vincula a los conflictos y divisiones con las clases sociales, conformando de esta manera, la sociedad moderna. Aunque la organización no tiene que ver con las relaciones de parentesco sino más bien con las divisiones de las clases sociales, divisiones en tanto trabajo, divisiones en tanto posesión. "La existencia de esas clases es consecuencia de la división del trabajo, de la separación entre los dueños de los medios de producción y productores, y de la amplitud del proceso de producción." (Mendel: 60).

Pensar en un individuo, implica analizarlo a partir de su esencia, de lo natural, de lo biológico, en definitiva a partir de la sustancia. Pensar en un individuo, es analizarlo sólo desde su composición estructural en tanto estructura biológica de un cuerpo que posee músculos, articulaciones y órganos. Es el cuerpo de la medicina puesto que "el saber de la medicina constituye una práctica a partir de un conjunto de relaciones que van conformando un tipo de objeto, 
determinados conceptos y estrategias que se organizan de forma correlativa con la política". (Emiliozzi, 2016)

Si suponemos que el individuo es portador de derechos, esto responde a que a priori tiene derechos, es decir hay algo o alguien que le brinda, le porta esos derechos. De esta manera inferimos que "el sujeto se constituye siempre a partir de una sustancia primera que luego es atravesada por la política, por el derecho (...), y luego por la palabra" (Emiliozzi, 2016:149)

No obstante, si lo analizamos a partir de un sujeto de derechos, parecería, a simple vista que estamos en frente de otra significancia en términos de sujeto y en términos de derecho, cuando en realidad la proposición no se modifica.

\section{- El sujeto de derechos}

Si admitimos un sujeto de derechos, continuamos en una misma línea de análisis retornando a una idea biologicista, esencial y natural del sujeto, puesto que este es constituido a partir de su nacimiento, reanudando al derecho natural por el hecho de ser humano. Esto ya era enunciado por Emiliozzi haciendo referencia al Diseño Curricular "son los derechos que el ser humano posee por su condición humana" (DGCyE, 2007b: 23), y

\footnotetext{
"Así se pone en evidencia que no sólo el ciudadano es considerado como un sujeto natural, sino que lo mismo sucede con los llamados derechos naturales, llevando al sujeto a un sentido material o biológico. La constitución del sujeto parte del reconocimiento de una sustancia viva." (2016: 78)
}

El Diseño Curricular actual del nivel inicial, también presenta sus aportes en este sentido, puesto que pretende "promover el desarrollo de los/las niños/as de cuarenta y cinco días (45) a cinco (5) años de edad inclusive, como sujetos de derechos y partícipes activos/as de un proceso de formación integral, miembros de una familia y una comunidad." (2019) 
En esta línea de análisis encontramos que el derecho al juego es tomado desde una episteme basada en la ciencia clásica cuyo predominio es el individuo, el signo, su esencia, su naturaleza; posicionando como consecuencia, el derecho al juego como una necesidad vital.

\section{- El juego como necesidad vital}

El concepto de "necesidad vital" se presenta actualmente en el derecho al juego como esencial, fundamental, única e indiscutida para la vida de los niños y niñas, para su aprendizaje y para su desarrollo. A partir de esto, se pone en tensión esta enunciación: el derecho al juego como "necesidad vital". Muchos son los autores, fundaciones y organizaciones que remiten a esta idea.

Por un lado, el derecho a jugar fue reconocido por primera vez el 20 de noviembre de 1959, cuando la Asamblea General de las Naciones Unidas aprobó la Declaración de los Derechos del Niño. Treinta años más tarde se aprobó la Convención de los Derechos del Niño, que recoge el derecho al juego en el artículo 31 estableciendo "el derecho del niño al descanso y el esparcimiento, al juego y a las actividades recreativas propias de su edad y a participar libremente en la vida cultural y en las artes". (C.D.N, 1990:30).

Por otra parte, observamos la reiterada conceptualización del juego, como la

"actividad motriz más espontánea del niño y del adolescente; mediante el juego efectúa movimientos naturales y emplea su energía recreándose. (...). Mediante el juego el niño obtiene conocimientos y experiencias, se ejercita aplicando impulsos innatos y poniendo a prueba sus capacidades, aptitudes y actitudes." (Baratti, Casali, 1991:15)

Este apartado, constituye uno de los tantos libros que conforman las repetidas bibliografías y concepciones sobre juego; en este caso el libro "Del Juego al deporte I. Actividades para el nivel primario", quien responde al 
discurso hegemónico del juego, pensándolo como medio para aprender un deporte y como elemento de movimientos naturales e innatos. La revista digital para profesionales de la enseñanza, de la Federación de Enseñanza de Andalucía sostiene la misma línea de pensamiento, la misma define al juego como la

"actividad necesaria para los seres humanos teniendo suma importancia en la esfera social, puesto que permite ensayar ciertas conductas sociales; siendo, a su vez, una herramienta útil para adquirir y desarrollar capacidades intectuales, motoras o afectivas. Todo ello se debe realizar de forma gustosa y placentera, sin sentir obligación de ningún tipo y con el tiempo y el espacio necesarios. El juego infantil es una necesidad básica para un buen desarrollo de la inteligencia y también para el equilibrio físico emocional del niño/a".

Dicha revista se basa en autores referenciales tales como Marchesi y Coll (1990) del libro "Desarrollo psicológico y educación". Alianza Editorial. Madrid; Blanco Sierra, Javier: (1992). "El juego infantil", Juan XXIII, Orense, Garaigardobil, M.(1990) "Juego y desarrollo infantil". Seco Olea, Madrid. Piaget, J. (1973). "La Psicología de la Inteligencia". Gallego Ortega, J.L. (1994). "Educación Infantil". Málaga. Aljibe. AAVV. Moyles J.R. (1990) "EI Juego en la educación infantil y primaria", Morata, Madrid. Ortega. R.: (1992) "El juego infantil y la construcción social del conocimiento", Alfar, Sevilla. Ortega, R.: (1990) “Jugar y aprender”, Diada, entre otros.

\section{- Los Diseños Curriculares de la Provincia de Buenos Aires}

Podemos observar en cada uno de los Diseños Curriculares vigentes y en sus niveles correspondientes, que el juego y su enseñanza se piensa a partir no sólo de una necesidad, sino también en vinculación a la edad de los sujetos que aprenden aquello que se les enseña.

Si bien el Diseño Curricular vigente de la Provincia de Buenos Aires del Nivel Inicial, presenta al juego en tanto práctica sociocultural y lo reconoce como 
objeto a enseñar, se observa cierta contradicción en su propuesta, puesto que sostiene "el juego como condición de aprendizaje". Es decir que, por un lado lo presenta como un saber a enseñar "como condición epistémica de los saberes que circulan" (2019: 18), y por otro lado, como condición indispensable para el aprendizaje de determinados contenidos educativos, ajenos al juego en sí.

La idea de analizar al juego a partir de su necesidad, "se condice con el marco legal que encuadra la prescripción curricular: Ley 13688, Capítulo III, artículo 26 , inciso c, que al respecto de las funciones y objetivos del Nivel Inicial enuncia: "Implementar prescripciones curriculares que incorporen al juego como actividad ineludible para el desarrollo cognitivo, afectivo, ético, estético, corporal y social". (Ibid, 2019: 24).

Es sabido que el curriculum señala e indica sentidos al prescribir las prácticas, tanto en el ejercicio de las mismas como en la formación profesional donde se imprimen esos sentidos. Los mismos se ven plasmados en cada uno de los Diseños, y en especial en el Diseño Curricular del Nivel Superior del profesorado de Educación Física de la Provincia de Buenos Aires. La cátedra de $1^{\circ}$ año "Didáctica de las Prácticas Lúdicas", propone los siguientes contenidos para pensar la enseñanza del juego:

- El juego tratado en los diferentes espacios y tiempos (como ámbitos y en sus diferentes momentos)

- El juego y los sujetos: los diferentes grupos etarios, con sus diferentes intereses y necesidades.

- El juego y sus particularidades: organizativas y de seguridad/ precaución

- El juego desde dos perspectivas: el docente y el alumno. Docente en concordancia ideológica/ práctica ante el juego, y alumno en concordancia con sus intereses y necesidades.

- Los diferentes tipos de juegos.

Por lo tanto, como dijimos anteriormente, en cada uno de los Diseños Curriculares vigentes se presentan contenidos educativos a enseñar en vinculación a las necesidades de los sujetos y al grupo etario al cual corresponde, los cuales en definitiva, se identifican con un individuo biológico. Es decir, "todas 
estas caracterizaciones que ligan al sujeto con la persona o el individuo, con lo orgánico del cuerpo, universalizan al sujeto y particularizan al contenido con el impracticable propósito de hacerlo significativo para cada alumno" (CrisorioEscudero, 2017: 145)

\begin{abstract}
"Sujeto y saber se articulan necesariamente en el currículum, cualquiera sea el lugar desde el que se mire y tanto si es entendido como un documento concreto, elaborado a priori para prescribir una enseñanza, como una configuración discursiva -cualquiera sea, pero siempre presente - que orienta una enseñanza, o como un conjunto de prácticas de enseñanza. Todo acto de transmisión de un saber y toda prefiguración de ese acto implican, obviamente, un saber y un sujeto". (Crisorio-Escudero, 2017: 9)
\end{abstract}

Entendemos que pensar el juego y su enseñanza desde la perspectiva de la necesidad y desde una edad cronológica, es decir a partir de un sujeto universal, conlleva a un problema epistemológico, que trataremos de analizar a continuación.

\title{
* La necesidad en el juego
}

Considerar al juego como derecho, implica pensarlo como necesidad en tanto biológica que supone un retorno a lo natural. Sería válido analizarlo de esta manera, puesto que cada uno de los pensamientos sobre el derecho que han sido plasmados con anterioridad, lo vinculan directamente con la naturaleza del ser humano. Y, al analizar las diferentes teorías que interpretan el derecho - en este caso en relación al juego - lo plantean sólo como necesidad y vitalidad: "los especialistas afirman que jugar es necesario y vital para lograr un equilibrio en su proceso de desarrollo" (UNESCO, 2007).

A su vez, se plantea que "jugar es tan vital para los niños y niñas como comer o respirar. Además de felicidad y diversión, al hacerlo se desarrollan 
capacidades físicas, emocionales, cognitivas y sociales" (FUNDACIÓN ARCOR, $s / d)$.

"El deporte, la recreación y el juego fortalecen el organismo y evitan las enfermedades. El derecho al deporte, juego y recreación constituye un estímulo para el desarrollo afectivo, físico, intelectual y social de la niñez y la adolescencia, además de ser un factor de equilibrio y autorrealización". (UNICEF)

"El juego es la principal actividad infantil. Jugar es una necesidad, un impulso vital, primario y gratuito, que nos empuja desde la infancia a explorar el mundo, conocerlo y dominarlo" (IPA ${ }^{6}$ ESPAÑA)

En el seno de las prácticas educativas, estos sentidos parecieran replicarse puesto que la influencia de ciertos enunciados vertidos desde la psicología, también con sentidos vitalistas - biologicistas, han instalado en la lógica que hace funcionar las prácticas que refieren al juego y al jugar del niño, una racionalidad que ha establecido un modo de pensarlos, de decirlos, de hacerlos, en fin, de practicarlos.

"La Educación Física basó sus prácticas lúdicas en aportes psicológicos clasificando los juegos con relación a la edad o nivel de desarrollo de los mismos, expresando un proceso evolutivo unilineal (por ejemplo, de los juegos simbólicos a los reglados), proceso que parece estar determinado por la genética y por una tendencia instintiva hacia el progreso." (Villa, Taladriz, Nella y Aldao, 2011:3)

Por su parte, la filosofía también ha aportado fuertemente sobre prácticas orientadas y pensadas en lo natural, en lo biológico y fisiológico

"En este sentido el niño es el paradigma de una vida que es absolutamente inseparable de su propia forma, una absoluta formade-vida sin resto (...) el niño nunca es nuda vida, que nunca es

\footnotetext{
${ }^{6}$ IPA: International Association for the Child's Right to Play. O bien, Asociación Internacional por el Derecho del niño a Jugar.
} 
posible de aislar en un niño algo como la nuda vida o la vida biológica". (Agamben, 2012: 25)

Si vinculamos el juego con uno de los referentes contemporáneos de la Educación Física en la Argentina, que han escrito y estudiado el jugar como derecho es Víctor Pavía. El autor, en uno de sus escritos, se pregunta a qué da derecho el derecho al juego, y propone en primer lugar que, el derecho al juego es derecho a espacios, tiempos y juguetes. En segundo lugar plantea que los niños y niñas tienen derecho a jugar de un modo lúdico y a estar cerca de adultos que sepan jugar de ese modo. Y continúa realizando una observación a la redacción en el artículo 31 de la Convención Internacional de los derechos del niño, donde plantea que,

"allí se con-funden necesidad con satisfactor. Si un derecho se
relaciona con una necesidad y, en este caso, la necesidad es de
descanso y esparcimiento, el juego actúa como satisfactor. De todas
maneras, con sus luces y sombras, el Artículo 31 se encuentra
reproducido en las paredes de innumerables escuelas. Digo luces
porque preservar el derecho al descanso y a la diversión a través del
juego constituye, a mi juicio, un avance cualitativo importante". (Pavía, 2010)

Si bien Pavía propone un profundo cambio al superar la idea del juego como recurso, y traspasa la pared del juego como medio para aprender otros contenidos, observamos que aunque efectivamente realiza un viraje hacia el juego como derecho se continúa en la misma línea que esta tesis trata de problematizar. La teoría que este trabajo propone es dar cuenta que el derecho en tanto satisfactor de necesidades implica un retorno a la naturaleza de lo humano, un retorno a lo natural del hombre pensando al derecho como un satisfactor de una necesidad, en este caso, del juego. 
Si nos permitimos profundizar en los alcances del concepto necesidad, el mismo remite también a esta mirada. Observamos que, según la RAE (2001), una necesidad surge cuando "existe un impulso imposible de controlar que lleva a que los esfuerzos individuales se encaminan en cierta dirección". Necesidad es "lo que hace falta para existir o para lograr algo": del latín necessitatem. (Gómez de Silva, 1998: 478). En síntesis, las necesidades son propias de todo organismo vivo y consisten en una sensación provocada por la idea de que nos falta algo ya sea a nivel material, orgánico o sentimental. Se las trata como uno de los componentes fundamentales en la vida, no sólo humana sino también de las demás especies; es la necesidad la que lleva a que los seres vivos se movilicen en busca de objetivos que les sirvan para satisfacer aquello que consideran que precisan. De allí la recurrente idea que cuanto más pequeño es el niño, más necesario será el uso del juego y más importante será esta herramienta en su vida. Los niños pequeños necesitarían jugar, moverse, desplazarse, experimentar, tocar, construir, deshacer para que luego supuestamente, aprendan a construir, imitar, bailar, cantar, imaginar, etc.

Max Neef por su parte, propone que

"concebir a las necesidades tan sólo como carencia, implica restringir su espectro a lo puramente fisiológico, que es precisamente el ámbito en que una necesidad asume con mayor fuerza y claridad la sensación de "falta de algo". Sin embargo, en la medida en que las necesidades comprometen, motivan y movilizan son también potencialidad, y más aún, pueden llegar a ser recursos" (Max Neef, 1994: 50).

En este caso, podríamos suponer que la necesidad de jugar es potencial del juego; de esta manera, las necesidades no se satisfacen ni se colman, sino que "revelan un proceso dialéctico el cual constituye un movimiento incesante, aunque no así un recurso" (Ibid, 1994: 50) puesto que, tomarlo como tal, implica utilizarlo como un medio para enseñar otros saberes. 
Si bien consideramos interesante la idea de Max Neef de plantear a las necesidades en términos de potencialidad, pues nos provoca a pensar la potencialidad en el juego; en definitiva, la etimología del término "necesidad" no nos aporta el compromiso, la motivación, ni la movilización como lo propone el autor. Y si analizamos un cuadro que él mismo construye, se observa cierta contradicción puesto que el término necesidad continúa retornando a una idea sustancialista del sujeto, volcando en un cuadro de doble entrada necesidades según categorías axiológicas (de subsistencia, de protección, afecto, etc), y de categorías existenciales (ser, tener, hacer, estar). 


\section{Cuadro Matriz de necesidades y satisfactores de Max Neef $e t a .1$}

\begin{tabular}{|c|c|c|c|c|}
\hline \multirow{2}{*}{$\begin{array}{l}\text { Necesidades } \\
\text { según categorias } \\
\text { axiológicas }\end{array}$} & \multicolumn{4}{|c|}{ Necesidades según categorias existenciales } \\
\hline & 1. Ser & 2. Tener & 3. Hacer & 4. Estar \\
\hline 1.Subsistencia & $\begin{array}{l}\text { Salud fisica, salud } \\
\text { mental, } \\
\text { solidaridad, equilibrio, } \\
\text { adaptabilidad }\end{array}$ & $\begin{array}{l}\text { Alimentación, abrigo, } \\
\text { trabajo }\end{array}$ & $\begin{array}{l}\text { Alimentar, procrear, } \\
\text { descansar, trabajar }\end{array}$ & $\begin{array}{l}\text { Entorno vital, } \\
\text { entorno social }\end{array}$ \\
\hline 2. Protección & $\begin{array}{l}\text { Cuidado, adaptabilidad, } \\
\text { autonomia, equilibrio, } \\
\text { solidaridad. }\end{array}$ & $\begin{array}{l}\text { Sistemas de seguros, } \\
\text { ahorro, seguridad social, } \\
\text { sistemas de salud, } \\
\text { legislaciones, derechos, } \\
\text { familia, trabajo }\end{array}$ & $\begin{array}{l}\text { Coopenar, prevenir, } \\
\text { planificar, cuidar, curar, } \\
\text { defender }\end{array}$ & $\begin{array}{l}\text { Contomo vital, contorno } \\
\text { social, morada }\end{array}$ \\
\hline 3. Afecto & $\begin{array}{l}\text { Autoestima, solidaridad, } \\
\text { respeto, tolerancia, } \\
\text { generosidad, } \\
\text { receptividad, pasión, } \\
\text { voluntad, sensualidad, } \\
\text { bumor }\end{array}$ & $\begin{array}{lr}\begin{array}{l}\text { Amistades, } \\
\text { familia, }\end{array} & \begin{array}{r}\text { parejas, } \\
\text { animales }\end{array} \\
\text { domisticos, } & \text { plantas, } \\
\text { jardines } & \end{array}$ & $\begin{array}{l}\text { Hacer el amor, acariciar, } \\
\text { expresar emociones, } \\
\text { compartir, cuidar, } \\
\text { cultivar, apreciar }\end{array}$ & $\begin{array}{l}\text { Privacidad, intimidad, } \\
\text { hogar, espacios de } \\
\text { encuentro. }\end{array}$ \\
\hline 4. Entendimiento & $\begin{array}{l}\text { Concienciar critica, } \\
\text { receptividad, curiosidad, } \\
\text { asombro, disciplina, } \\
\text { intuición, racionalidad. }\end{array}$ & $\begin{array}{lr}\text { Literatura, } & \text { maestros, } \\
\text { método, } & \text { politicas } \\
\text { educacionales, } & \text { politicas } \\
\text { comucacionales }\end{array}$ & $\begin{array}{l}\begin{array}{l}\text { Investigar, } \\
\text { experimentar, }\end{array} \\
\text { analizar, } \\
\text { educar, } \\
\text { interpretar. }\end{array}$ & $\begin{array}{l}\text { Ámbitos de interacción } \\
\text { formativa, escuelas, } \\
\text { universidades, } \\
\text { academias, } \\
\text { agrupaciones, } \\
\text { comunidades, familia }\end{array}$ \\
\hline 5. Participación & $\begin{array}{l}\text { Adaptabilidad, } \\
\text { receptividad, solidaridad, } \\
\text { disposición, convicción, } \\
\text { entrega, respeto, pasión, } \\
\text { humot }\end{array}$ & $\begin{array}{l}\text { Derechos, } \\
\text { responsabilidades, } \\
\text { obligaciones, trabajo }\end{array}$ & 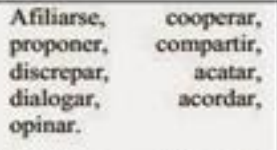 & $\begin{array}{l}\text { Ámbitos de interacción } \\
\text { participativa, partidos, } \\
\text { asociaciones, iglesias, } \\
\text { comunidades, } \\
\text { vecindarios, familias }\end{array}$ \\
\hline 6. Ocio & $\begin{array}{l}\text { Curiosidad, receptividad, } \\
\text { imaginación, } \\
\text { despreocupación, humor, } \\
\text { tranquilidad, sensualidad }\end{array}$ & $\begin{array}{l}\text { Juegos, espectículos, } \\
\text { fiestas, calma }\end{array}$ & $\begin{array}{l}\text { Divagar, abstraerse, } \\
\text { sotiar, afforar, fantasear, } \\
\text { evocar, relajarse, } \\
\text { divertirse, jugar. }\end{array}$ & $\begin{array}{l}\text { Privacidad, intimidad, } \\
\text { espacios de encuentro, } \\
\text { tiempo libre, ambientes, } \\
\text { paisajes. }\end{array}$ \\
\hline 7. Creación & $\begin{array}{l}\text { Pasión, } \\
\text { intuición, imaginación, } \\
\text { audacia, racionalidad, } \\
\text { autonomia, inventiva, } \\
\text { curiosidad. }\end{array}$ & $\begin{array}{l}\text { Habilidades, destrezas, } \\
\text { método, trabajo }\end{array}$ & $\begin{array}{lr}\text { Trabajar, } & \text { inventar, } \\
\text { construir, } & \text { idear, } \\
\text { componer, } & \text { diseñar, } \\
\text { interpretar } & \end{array}$ & $\begin{array}{l}\text { Ámbitos de producción } \\
\text { y retroalimentación, } \\
\text { talleres, ateneos, } \\
\text { agrupaciones, } \\
\text { audiencias, espacios, de } \\
\text { expresión, libertad } \\
\text { temporal }\end{array}$ \\
\hline 8. Identidad & $\begin{array}{l}\text { Pertenencia, coherencia, } \\
\text { diferenciación, } \\
\text { autoestima, asertividad. }\end{array}$ & $\begin{array}{l}\text { Simbolos, lenguajes, } \\
\text { híbitos, costumbres, } \\
\text { gnupos de referencia, } \\
\text { sexualidad, valores, } \\
\text { normas, roles, memoria } \\
\text { histórica, trabajo }\end{array}$ & $\begin{array}{l}\text { Comprometerse, } \\
\text { integrarse, confrontarse, } \\
\text { definirse, conocerse, } \\
\text { reconocerse, } \\
\text { actualizarse, crecer }\end{array}$ & $\begin{array}{l}\text { Socio-ritmos, entomos } \\
\text { de la cotidianeidad, } \\
\text { ámbitos de pertenencia, } \\
\text { etapas madurativas }\end{array}$ \\
\hline 9. Libertad & $\begin{array}{l}\text { Autonomia, autoestima, } \\
\text { voluntad, pasión, } \\
\text { asertividad, apertura, } \\
\text { determinación, audacia, } \\
\text { rebeldia, tolerancia. }\end{array}$ & Igualdad de derechos & $\begin{array}{l}\text { Discrepar, optar, } \\
\text { diferenciarse, arriesgar, } \\
\text { conocerse, asumirse, } \\
\text { desobedecer, meditar }\end{array}$ & $\begin{array}{l}\text { Plasticidad } \\
\text { temporal. }\end{array}$ \\
\hline
\end{tabular}

Fuente: Max Neef et al., Desarrollo a escala humana, p.42.

Retomando el posicionamiento de las teorías biologicistas donde vinculan al juego como una necesidad vital planteado en el apartado anterior, analizaremos a continuación el concepto de vitalidad. 


\section{* La vitalidad en el juego}

Por su parte, la vitalidad es lo relativo a la vida, es lo necesario para seguir viviendo. El vocablo proviene del latín vitalis, de vita: vida. Refiere a una condición que solemos disponer las personas y que implica la presencia de vigor, de energía en todo cuanto se realiza y en la eficacia con respecto a las funciones vitales. Contar con vitalidad hará que aquello que se lleve a cabo se ejecute con ímpetu especial, y por ende es esperable que su resultado sea extraordinario. Asimismo, se pone en juego toda la energía que ella le dispensa, consiguiendo así la consecución de su objetivo de modo satisfactorio.

Tomando la expresión vita activa que plantea Arendt (2008: 8), haciendo hincapié concretamente en las tres actividades fundamentales que la componen labor, trabajo y acción - y poniendo particularmente el acento en la primera, la autora señala que "es la actividad correspondiente al proceso biológico del cuerpo humano, cuyo espontáneo crecimiento (...) están ligados a las necesidades vitales producidas y alimentadas por la labor en el proceso de la vida". Desde esta perspectiva, observamos que al juego y su derecho a, se lo ha posicionado como una actividad vinculada a la labor, como posesión de un cuerpo libre y espontáneo, desde donde se visualizan que las diferentes teorías que analizan el derecho al juego se componen de una necesidad vital, de un retorno a lo natural; "es decir, todos los discursos refieren a la creencia de una naturaleza biológica o lo que es decir una naturaleza humana". (Giles, 2017: 62)

En este mismo recorrido donde los discursos que circulan refieren a lo natural de lo humano, remiten así a razones esenciales en la vida del hombre, emergiendo de esta manera, concepciones de derechos en torno a ideas como igualdad y equidad, las cuales no se alejan de este posicionamiento y quienes autores como Badiou nos permiten analizar. 


\section{- Dos caras de una misma moneda, entre la igualdad y la equidad}

Siguiendo a Badiou:

"Llamamos hombre a aquel que tiene la larga paciencia del pensamiento y de la acción. Cuando se concibe así al hombre - el hombre que es capaz de hacerse a sí mismo, el hombre que es capaz de inventarse a sí mismo-, entonces decimos sí, este hombre, esta humanidad, tiene derechos, tiene derechos profundos y esenciales. Es el derecho que tiene la humanidad de crearse a sí misma y no estar siempre sometida a poderes exteriores." (Badiou, 2000)

A partir de lo expresado, el autor plantea que los "derechos del hombre son los derechos al no-Mal: no ser ofendido y maltratado ni en su vida (horror a la muerte y a la ejecución), ni en su cuerpo (horror a la tortura, a la sevicia y al hambre), ni en su identidad cultural (horror a la humillación de las mujeres, de las minorías, etc.)" (2004:4) y propone en contrapartida, "producir la mayor cantidad de igualdad posible", aunque la igualdad implica recibir el mismo trato sin considerar las diferencias. El sistema capitalista transmite diariamente que la igualdad no existe, puesto que es "normal" las diferentes luchas, la competencia; para el autor "la "humanidad" es producir igualdad, es la única digna del hombre, es la única que crea verdaderos derechos humanos" (Badiou, 2000: 5)

Igualdad también implica tener el mismo trato ante la ley; aunque podríamos anexar a esta idea de igualdad, la de equidad, que permite analizar esa igualdad en términos de que -además de recibir el mismo trato- recibe lo que a cada uno le corresponde, es decir, se compromete con las diferencias.

Para una mayor precisión, nos adentraremos a comprender el significado de estos conceptos, a partir de su origen etimológico. 'Igualdad' del latín "aequalìtas", que literalmente significa "equilibrado, relativo", lo que podemos entender que su significado es el principio o condición que reconoce una equiparación en cuanto a derechos y obligaciones de todas las partes que 
conforman un todo. Por su parte, 'equidad' proviene del latín "aequss" que quiere

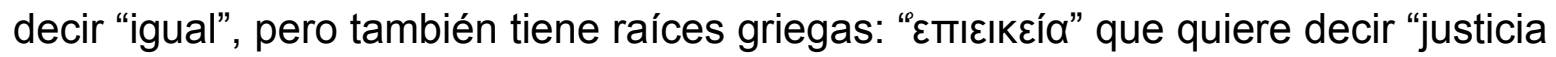
en el caso correcto". Por lo que la definición de equidad es repartir de forma proporcional lo que cada uno necesita, ni más, ni menos. Este concepto engloba algo mucho más allá, pues considera que para alcanzar el estado de libertad se debe incluir a la justicia: conseguir que todos seamos iguales en nuestras particularidades, teniendo en cuenta nuestras diferencias y respetando cada una de ellas.

A partir de las ideas presentadas por Badiou, acerca de cómo fue constituida la teoría del hombre y en consecuencia del derecho; podemos pensar que este último ha sido implementado por aquellos sujetos de la sociedad no vulnerados, los mismos que alimentan la desigualdad social y la división de clases sociales. Esto representa las dos caras de una misma moneda, donde la moneda son los derechos, una de las caras quienes otorgan y la otra, los portadores de esos derechos.

Por último, como se planteó al principio de este trabajo en referencia a la genealogía, en este caso a la genealogía del derecho, los mismos se manifiestan en cada una de las prácticas de derecho, las referencias a las relaciones de poder y a las relaciones en tanto saber.

\section{- El derecho como sujeto}

A partir del análisis realizado sobre el "individuo portador de derechos" y el "sujeto de derechos", nos proponemos presentar un análisis diferente que se contrapone a las premisas anteriores, el "derecho como sujeto". A partir de los dichos y escritos de Lacan ${ }^{7}$, indagaremos en el término sujeto, que, desde este posicionamiento, nos servirá de sustento para fundamentar y problematizar la teoría del Derecho como sujeto.

\footnotetext{
7 Jacques-Marie Émile Lacan fue un médico psiquiatra y psicoanalista francés. (1901-1981)
} 
Lacan afirma que el psicoanálisis es un tratamiento que se dirige al sujeto de derecho como tal, al sujeto de pleno derecho. Lo sitúa a partir de que el sujeto es quien da una respuesta, posee la capacidad de respuesta. El término sujeto se introduce a partir del derecho, es decir a partir de que un sujeto puede decir "tengo derecho a".

Por lo tanto, el sujeto que aquí interesa no es el sujeto en la medida en que "hace el discurso", más bien es el sujeto "que está hecho por el discurso, e incluso está atrapado en él, es el sujeto de la enunciación". (Lacan, 2007: 53). En otras palabras, el significante es efecto del sujeto porque "el significante es lo que representa al sujeto para otro significante, no para otro sujeto" (íbid: 53); a diferencia del signo que este representa al individuo, como se expuso anteriormente. Y, "para poder orientarse en cuanto al funcionamiento del sujeto, hay que definir este Otro como el lugar de la palabra. No es desde donde la palabra se emite, sino donde cobra su valor de palabra" (Ibid.: 54).

"Todo ser hablante, en la medida que es apresado por un orden simbólico, queda marcado en lo sucesivo por el significante, de un modo tal que sufre una mortificación. (...) Una vez que un ser hablante, el ser humano, es apresado por ese sistema, no sólo pierde su relación a la necesidad, sino que pierde toda posibilidad de enteridad, de totalidad, de completud, de ser "todo"." (Crisorio, 2018: 13)

De este modo, "la estructura del lenguaje no es articulable con la lógica individualista, porque no hay nada que provenga de una esencia, naturaleza o interior." (Emiliozzi: 2016: 131)

Pensar en el Derecho como sujeto, engloba la idea de que el sujeto está atrapado en su derecho, puesto que está hecho por el discurso del derecho.

Analizar el derecho de esta manera, implica tomar distancia de las divisiones de clases, implica tomar distancia de un Otro superior y uno inferior, implica tomar distancia de los posicionamientos vitalistas y naturalistas del cual se cree que se constituye el sujeto en tanto origen -también- divino. Y, por otra parte, implica acercarse a una idea de sujeto producto del significante, pero que a su vez 
escapa al significante, "Porque lo primero que acontece a un sujeto cuando lo aprisiona el sistema significante es una falta. La falta es la marca en el ser humano de la acción de lo simbólico; esa acción crea la idea, el concepto, de falta, de presencia-ausencia, de algo que puede estar y no estar, ser y no ser" (Crisorio, 2018: 13)

A partir de esa idea se crea la concepción en tanto derecho, pero no del Sujeto de Derecho, sino más bien de El Derecho como Sujeto. Si bien podríamos pensar que de esta forma el sujeto se constituye atravesado por la política, por el derecho y se aparta de un sujeto como sustancia primera, podemos aclarar que a pesar de los grandes esfuerzos realizados por organizaciones y pensamientos en pos de brindar ciertos derechos, -en este caso al juego- se continúa una línea de pensamiento donde el derecho sigue siendo sustancial, natural y esencial.

Pero, por otro lado, si pensamos en la posición de El Derecho como Sujeto, modificando la fórmula, nos permite suponer que hay un Estado garante de ciertos derechos. Es decir, a priori hay derechos que son o deberían ser garantizados por un Estado presente; es por ello su modificación, su cambio de lugar. Por lo tanto, nos corremos de cualquier idea de Sujeto de Derecho y en consecuencia de el Juego como Derecho, para poder posicionarnos claramente sobre el Juego en tanto práctica cultural y por ende corporal.

Y si lo vinculamos con la Práctica Corporal Juego, este responde a un sujeto jugado, puesto que

"El concepto de prácticas que asumimos no supone un sujeto practicante, que precede a las prácticas y las realiza; antes bien, indica un sujeto practicado, precedido por las prácticas y realizado en ellas." (Crisorio; 2018: 7).

Por lo tanto, pensamos ${ }^{8}$ en un sujeto "jugado", precedido por el juego y realizado en ellas. Con esta enunciación de sujeto jugado, realizamos un

\footnotetext{
${ }^{8}$ EI GIJ (Grupo de Investigación en Juego), en su libro: “Una teoría del juego en la educación: Tras su dimensión estética, ética y política", proponen de la misma manera, a un sujeto jugado tal cual lo plantea esta tesis. Villa, M.; Nella, J.; Taladriz, C.; Aldao, J. (2020). La Plata: Universida Nacional de La Plata. Facultad de Humanidades y Ciencias de la Educación. (Estudios-Investigaciones; 72 ).
} 
desplazamiento de pensar el juego desde la perspectiva de los jugadores y desde la perspectiva del derecho, a pensar al juego como práctica cultural, en tanto práctica corporal.

Apostar a este posicionamiento, implica pensar la enseñanza de las Prácticas Corporales en general, y del Juego en particular desde otra perspectiva, nos permite analizarlas como un saber. Saber entendido como

"aquello de lo que se puede hablar en una práctica discursiva que así se encuentra especificada: el dominio constituido por los diferentes objetos (...); un saber es también el espacio en el que el sujeto puede tomar posición para hablar de los objetos de que trata en su discurso (...); es el campo de coordinación y subordinación de los enunciados en que los conceptos aparecen, se definen, se aplican y se transforman (...); en fin, un saber se define por posibilidades de utilización y de apropiación ofrecidas por el discurso (...), pero no existe saber sin una práctica discursiva definida; y toda práctica discursiva puede definirse por el saber qué forma.' (Foucault, 2007: 237-238)

Si nos enmarcamos en el P.I.C.- Programa de Investigación Científicadenominada Educación Corporal; "es decir, en el marco de una teoría que entiende al juego como saber a enseñar (...), y que consecuentemente debe encontrar en él un saber digno de ser enseñado, un contenido valioso". (Crisorio, 2019 inédito). "Ese valor sólo puede ser del orden del saber y no del desarrollo -de la personalidad, del organismo, de sus percepciones, su inteligencia" (Ibid). Es por ello que el término Derecho se inscribe anterior al saber, puesto que el Derecho no es del orden del saber.

Este Programa plantea al juego y su enseñanza en tanto saber valioso, no en tanto derecho como lo proponen las pretenciosas teorías que sustentan la idea de derechos, en especial aquellas que circulan en los Diseños Curriculares de la provincia de Buenos Aires, quienes no sólo se enmarcan en una mirada esencial y 
vitalista del juego, sino también como mediador de ciertos contenidos educativos. Los siguientes apartados, son algunos de los ejemplos que Diseño Curricular del Nivel Primario del año 2008, plantea,

- "Reconocer el derecho de cada niño y niña al juego y a la actividad motriz, valorar las posibilidades de cada integrante del grupo supone partir del "yo puedo" de cada niño y niña y propiciar "el placer por el hacer motor",

- "Se espera que los niños/as, en tanto sujetos de derecho, merecedores de dignidad y respeto como miembros activos de la comunidad, cuenten con una propuesta que conciba al sujeto/niño/a como ciudadano, que les permita acceder a prácticas corporales, motrices y lúdicas haciéndolas propias para modificarlas o inventando nuevas alternativas convirtiéndose en portadores y creadores de cultura". (2008: 74)

- "En el espacio común de la clase de Educación Física, el/la docente ha de propiciar que todos los niños y niñas ejerzan el derecho a disfrutar con sus compañeros del aprendizaje de saberes corporales y ludomotrices, sean reconocidos en su singularidad, con sus intereses, posibilidades y limitaciones, de modo que se los habilite a elegir las propuestas que más les agrade aprender fuera del tiempo escolar, en el marco de una educación concebida como un proceso integral y permanente" (Ibid: 77)

En vinculación a estos ejemplos, lo cuales presentan un posicionamiento teórico, podemos plantear una categoría de análisis denominada: la Mediación del juego.

* La Mediación del juego

Esta categoría se caracteriza por indagar por un lado, al juego como recurso, como medio a enseñar y por otro, al juego como saber a enseñar en el campo de la educación física.

No es novedoso pensar el juego en el nivel inicial como un concepto que atraviesa la enseñanza de todas las áreas. Específicamente en el área Educación Física, el juego se presenta como un elemento imprescindible en su enseñanza. 
Por ejemplo, el Diseño Curricular de Educación Física de la provincia de Buenos Aires plantea que "la modalidad en que se llevan a cabo las prácticas de la educación física deben ser esencialmente lúdicas" (2008: 230, las cursivas son nuestras).

Dentro del período escolar del nivel inicial comprendido entre los 3 y 5 años, es un espacio que -en primera instancia- se caracteriza por ser un ambiente socializador en donde los niños dejan de estar permanentemente con su familia, a pasar a jugar y a compartir su tiempo con otros niños de su misma edad. Es en este momento en donde el juego con él y los otros parece tomar un lugar preponderante, teniendo en cuenta el Diseño Curricular del Nivel Inicial.

Por otro lado, el Diseño Curricular vigente de este nivel hace especial referencia al sentido y a la importancia del juego en este momento de la vida de los niños/as, proponiendo que "desde el supuesto de que el juego es un modo inexcusable de hacer y aprender, este se despliega en el Jardín de Infantes como la actividad central, con el propósito de potenciar así el desarrollo cognitivo, afectivo, estético, corporal y social de los niños". (2009: 18)

A su vez, el mismo diseño, clasifica a los juegos y los organiza en: juego centralizado, como la actividad que puede tener por objetivo promover el desarrollo de contenidos lúdicos de otras áreas, como por ejemplo matemática y/o prácticas del lenguaje; juego trabajo, actividad en la que se recrea un aspecto de la realidad; por ejemplo: la verdulería, la sala de primeros auxilios, etc.; y por último, el juego en sectores, organizado a partir de los materiales que se ofrecen en los distintos lugares y espacios de la sala, permitiendo la libre elección por parte de los niños y la exploración de distintos tipos de materiales y propuestas, dando lugar a la conformación de distintos subgrupos.

Esta posición teórica sobre el juego se asienta en ubicar a esta práctica en un lugar relevante en el ámbito escolar. Tal como proponía el pedagogo romanticista Federico Fröebel en su libro "La educación del hombre" en 1826,

"Síguese de ahí claramente que el juego, en esta edad, desarrolla el niño y contribuye a enriquecerle de cuanto le presentan su vida interior y la vida de la escuela; por el juego se abre al gozo y para el 
gozo, como se abre la flor al salir del capullo; porque el gozo es el alma de todas las acciones de esta edad.

Los juegos son, en su mayoría, ora juegos corporales, que ejercitan las fuerzas y la flexibilidad del cuerpo, ora la expresión del valor interno de la vida, del goce de la vida, que ejercitan el oído, o la vista (como los juegos de escondite, etc.), ora juegos de tiro y de ballesta, juegos de pintura y de dibujo; o también pueden ser juegos de ingenio, juegos de reflexión y de cálculo, etc. Todos ellos deberán dirigirse de suerte que respondan al espíritu del juego mismo, y a las necesidades del niño". (Froëbel en Hailmann, 2003: 135)

El ingreso del juego a la vida escolar argentina, podemos observarlo en los primeros jardines de infantes en el país, específicamente en febrero de 1870 quien Juana Manso funda el primer jardín de infantes subvencionado por el Estado en la Ciudad de Buenos Aires, en el que se introduce el método froebeliano. Ella plantea a sus contemporáneos la importancia de la educación mixta, de los jardines de infantes, del aprendizaje placentero y el recreo.

"A fines del siglo XIX y principios del siglo XX, la creación de jardines y cursos de formación de docentes para el kindergarten fueron causa de luchas protagonizadas por mujeres que debieron superar innumerables obstáculos para ejercer como maestras de los más pequeños y defender los espacios de su capacitación. Al mismo tiempo, las kindergarterinas se hacían eco de una nueva concepción de infancia: afirmando la educabilidad del niño, considerando las bondades de la enseñanza por medio del juego y no así del conocimiento y la razón". (DGCyE, 2007).

Aunque los inicios de las producciones académicas que comenzaron a analizar y estudiar al juego como objeto de estudio, provienen del Instituto JeanJacques Rousseau en la Universidad de Ginebra en 1912, por Claparède; en 
donde luego fueron reconocidos como teorías clásicas del juego a pesar de que su objeto no fuera el juego sino el desarrollo humano.

Como señala Ivana Rivero:

"Este instituto dio lugar al Instituto de Ciencias de la Educación, donde se realizaban investigaciones de psicología educativa dirigidas por Piaget desde 1921 hasta que fue nombrado director del instituto en 1935. Es aquí donde consiguen reconocimiento un conjunto de producciones provenientes de los campos de la biología (Spencer, Groos, Lazarus) y de la psicología (Hall, Claparède, Freud, Buytendijk), que serán reconocidas. Spencer será un autor que arrastra al campo educativo incidencias de la filosofía de la evolución y tendrá su arrastre al campo de la educación física (Galak, 2016). Este ha sido el discurso dominante sobre juego en el campo educativo que lo colocó en el lugar de instrumento o medio para enseñanza de otros saberes". (Rivero, 2020: 9)

Sin embargo, nadie nace sabiendo jugar, de allí que los juegos puedan pensarse como "tradiciones públicas" (Stenhouse, 1991), es decir como parte del "capital intelectual, emocional y técnico con que cuenta la sociedad" (Ibíd,) y que la cultura debe transmitir. No obstante, este se utiliza - en el sentido literal de la palabra - sólo como un medio para aprender otros contenidos. Se usa al juego como herramienta para aprender habilidades, técnicas, capacidades motoras, valores, etc y no como un saber a enseñar, para enseñar a jugar ese/esos juegos. Es responsabilidad de los maestros especializados en el tema enseñarles a jugar el/los juegos y, de esta manera proponer diversas formas de jugar un juego. Pensar el derecho al juego dentro del ámbito escolar, permite analizarlo como un proceso de racionalización, comprendido por un sistema complejo de elementos que articula el cuerpo y el currículum. En definitiva esta maniobra con el derecho al juego dentro del ámbito escolar pretende "mostrar el cuerpo totalmente impregnado de historia, y la historia impregnando al cuerpo" (Foucault, 2004: 32). 
El juego no sólo ha sido pensado como mediador en diversas áreas de la educación, sino también hacia el interior de la educación física. Como señalamos anteriormente el juego aparece en las prácticas como medio de la gimnasia, usando al mismo como recurso para aprender variadas habilidades motoras, para mejorar la técnica, o bien para desarrollar la fuerza, la velocidad, la resistencia y la flexibilidad.

Por otro lado, el deporte no queda por fuera de este análisis, aquí el juego también ha sido y es recurso del mismo, puesto que "no existe ningún deporte de conjunto que no necesite de los juegos para una mejor ejercitación de sus fundamentos". (Casalli-Baratti, 1991: 15) Tal es así que se propone específicamente en la iniciación deportiva a la siguiente combinación: juego simple-juego deporte-deporte propiamente dicho. Esto significa respetar las características cronológicas de cada niño y niña. Por su parte "el juego simple es una actividad necesaria del alumno/a y carece de reglas complejas". (Ibid, 1991: 17). Se enseña a partir de los $6 / 7$ años. En el juego deporte o juego reglamentado, la comunicación motriz adquiere mayor complejidad. Se enseña entre los 9 y 11 años. $\mathrm{Y}$ por último, el deporte propiamente dicho donde se enseña fundamentalmente entre los 11 y 12 años.

Si bien, no ahondaremos en esta tesis de manera profunda a una crítica hacia la iniciación deportiva, creemos pertinente afirmar que el deporte ha promovido y promueve el uso del juego como medio para sus fines deportivos, posicionando al juego en desmedro del deporte.

Entre 1960 y 1970, la construcción de la noción de "predeporte" tuvo una gran importancia. Dicha noción es definida como "juegos de gran intensidad que constituyen eslabones que conducen al muchacho (en el camino de su formación general) hacia la práctica de los deportes, motivo por el cual les podemos llamar predeportivos". (Devis y Sánchez 1996: 159)

Si pensamos al juego como un puente hacia los deportes, veríamos que el mismo toma el rol de transferencia, es decir, aquello que se enseña como juego, se transfiere al deporte. Por lo tanto, se presenta aquí una problemática puesto que en primera instancia, la transferencia no actúa de manera ni directamente, ni relativamente proporcional en la enseñanza del 
juego hacia el deporte. Porque en la enseñanza de los juegos predeportivos, no se enseñan juegos y no se enseñan deportes, entendiendo a éstos últimos como un "conjunto constituido por elementos que lo configuran como una práctica corporal”. (Bravo, 2018: 57).

En los juegos predeportivos se asume como sustento de su enseñanza, "la existencia de una transferencia que va de estos juegos a los deportes, ya sean individuales o colectivos, y se refieren al aprendizaje técnico y táctico o a las cualidades físicas, morales e intelectuales". (Ibíd).

Por lo tanto, la enseñanza de los juegos predeportivos, se sustenta en teorías biologicistas, donde el desarrollo de los niños y niñas y sus posibilidades de aprendizaje en torno a su edad, son sus pilares esenciales.

Hemos problematizado los diversos posicionamientos del derecho en general y del derecho como juego en particular. Por un lado, el derecho se piensa a partir de su esencia, de su naturaleza, lo cual nos convoca a un problema, puesto que, el derecho se ha constituido y se constituye como un elemento natural y esencial en la zoé ${ }^{9}$ de los individuos. Luego, desde esta misma línea de análisis se pensó el derecho al juego como recurso de enseñanza, lo que implica otra problemática en términos teóricos.

El hecho de poder desprendernos de pensar al juego como derecho, por su perspectiva naturalista y mediadora, nos habilita a analizarlo también desde un tercer problema: observamos que el derecho implica ser un dispositivo de poder, en términos foucaultianos. $Y$ en este problema, se constituye otro objeto a investigar, otro objeto a pensar ya que "el pensamiento es la libertad con respecto a lo que se hace, el movimiento mediante el cual nos desprendemos de ello, lo constituimos como objeto y lo reflejamos como problema". (Foucault, 2001)

\footnotetext{
${ }^{9}$ En términos filosóficos, el pensador Giorgio Agamben lo plantea de la siguiente manera: los griegos diferenciaban bios y zoe. "Bios hace referencia a la manera de vivir propia de un individuo o de un grupo al estilo que le es propio; zoe, en cambio, al hecho de vivir común a todos los vivientes".
} 
En el próximo capítulo, analizaremos dicho problema. Es decir, ¿qué es un dispositivo para Foucault?, ¿qué es un dispositivo de poder?, y ¿cuál es su vinculación con el Derecho y, en consecuencia, con el Juego? 


\section{CAPÍTULO III}

\section{EL DERECHO COMO DISPOSITIVO DE PODER}

A partir del análisis realizado en el capítulo anterior, podemos vincular al Juego en tanto Derecho con los aspectos que plantea Foucault para delimitar al término dispositivo. A su vez, el Derecho en tanto dispositivo, se sujeta primordialmente al dispositivo de poder.

En este capítulo analizaremos, qué es un dispositivo de poder y cuál es su vinculación con el Derecho y con el Juego.

Un dispositivo es

"es [...] un conjunto resueltamente heterogéneo que compone los discursos, las instituciones, las habilitaciones arquitectónicas, las decisiones reglamentarias, las leyes, las medidas administrativas, los enunciados científicos, las proposiciones filosóficas, morales, filantrópicas. En fin, entre lo dicho y lo no dicho, he aquí los

elementos del dispositivo. El dispositivo mismo es la red que tendemos entre estos elementos. [...] Por dispositivo entiendo una suerte, diríamos, de formación que, en un momento dado, ha tenido por función mayoritaria responder a una urgencia. De este modo, el dispositivo tiene una función estratégica dominante [...]. He dicho que el dispositivo tendría una naturaleza esencialmente estratégica; esto supone que allí se efectúa una cierta manipulación de relaciones de fuerza, ya sea para desarrollarlas en tal o cual dirección, ya sea para bloquearlas, o para estabilizarlas, utilizarlas. Así, el dispositivo siempre está inscrito en un juego de poder, pero también ligado a un límite o a los límites del saber, que le dan nacimiento pero, ante todo, lo condicionan. Esto es el dispositivo: 
estrategias de relaciones de fuerza sosteniendo tipos de saber, y [son] sostenidas por ellos". (Foucault, 1977: 298)

Analizar al juego en tanto derecho y a este último, como dispositivo de poder, nos invita a indagar sobre los aspectos que propone Foucault para delimitar a este término.

Como primera instancia, el autor propone que el dispositivo implica una red de relaciones que se establecen entre elementos heterogéneos: instituciones, leyes, enunciados científicos, proposiciones filosóficas, etc. Como segunda instancia, establece la naturaleza del nexo que puede existir entre estos elementos. Tercero "se trata de una formación que en un momento dado ha tenido por función responder a una urgencia. El dispositivo tiene así una función estratégica" (Castro, 2004: 98). Cuarto, un dispositivo se define por su génesis, y lo detalla en dos momentos esenciales: "un primer momento del predominio del objetivo estratégico; un segundo momento de la constitución del dispositivo propiamente dicho" (Ibid, 2004: 99). Por último, "el dispositivo, una vez constituido permanece tal en la medida en que tiene lugar un proceso de sobre determinación funcional: cada efecto, positivo o negativo, querido o no querido, entra en resonancia o contradicción con los otros y exige un reajuste" (Ibid, 2004: 99).

A continuación, consideramos cada una de dichas nociones o aspectos, para poder analizar el problema que acontece pensar el juego como derecho.

Con respecto al primer aspecto que caracteriza a un dispositivo, podríamos afirmar que el Derecho implica una red de relaciones que se fueron estableciendo a lo largo de toda la tesis, desde instituciones en tanto jurídicas quienes escriben leyes, es decir lo dicho, para definir qué es el Derecho en ese campo, o bien qué es el derecho al juego en la Convención de los derechos del niño, niña y adolescentes. Por otro lado, nos encontramos en esta red de relaciones vinculadas a las proposiciones filosóficas, morales, filantrópicas, es decir lo no-dicho, lo no escrito, la no ley. 
En relación al segundo aspecto, a la naturaleza del nexo que pueda existir entre dichos elementos, esta tesis ha podido dar cuenta, de cómo se ha ido constituyendo el derecho y el juego, y sus vinculaciones en relación a pensar el enunciado "Derecho al juego" como una necesidad vital. El año en donde nos encuentra finalizando esta tesis -2020-, es un año de pandemia mundial, y el binomio derecho-juego, se ha fundamentado directamente a las necesidades vitales de los niños y las niñas a jugar. Se observan no sólo videos donde dan cuenta de la necesidad de salir a jugar y estar al aire libre, sino también se verifican documentos las cuales fundamentan dicha posición. Una de ellas, la cual creemos que es la más importante o con mayor relevancia, es la creación del "Programa Nacional de Derecho al Juego: JUGAR", organizado y dirigido por el Ministerio de Desarrollo Social. Secretaría Nacional de niñez, adolescencia y familia. Resolución -2020-714APN-SENNAF\#MDS. El mismo propone que

"el juego es un medio de socialización que conjuga emociones, sentimientos, experiencias, conocimientos y relaciones interpersonales, donde los niños, niñas y adolescentes aprenden a conocerse a sí mismos e interactuar con los demás. Por ello, la promoción y efectivización del derecho al juego y a las actividades recreativas debe desarrollarse como política pública integral. De allí surge la necesidad de profundizar junto con los gobiernos provinciales y locales, así como junto a las organizaciones sociales y comunitarias, la comprensión acerca del valor que tienen las actividades lúdicas durante el desarrollo de la infancia. El juego, el jugar, constituye un aspecto fundamental en el desarrollo pleno y saludable de la infancia y la adolescencia desde su enfoque integral. Se constituye también en condicionante para el desarrollo y construcción de la propia identidad, como así también para la socialización con el entorno y la identidad colectiva, ya que permite nuevas formas de aprehender el mundo". (SENAF, 2020). 
Con respecto al tercer aspecto sobre la delimitación del dispositivo, lo cual trata de una formación que en un momento dado ha tenido por función responder a una urgencia, el dispositivo tiene así una función estratégica. Observamos que el juego como derecho ha sido una función estratégica para responder la urgencia de los discursos epocales de pensar al juego como recurso. "En los últimos años -y en virtud del auge que corrientes pedagógicas "renovadoras" tuvieron en nuestro país- el interés de los docentes por el juego se fue focalizando casi con exageración en aspectos relacionados con su aprovechamiento para la enseñanza, en la búsqueda de los recursos didácticos más eficientes" (Pavía, 1995: 66). Es decir, el juego como recurso se encontraba - y se encuentra-, en los discursos pedagógicos para luego enseñar ciertos contenidos educativos. Autores como Víctor Pavía, han podido dar cuenta de este problema y han propuesto otra teoría vinculando al juego a la perspectiva de derecho.

En palabras del autor,

"el derecho al juego de niñas y niños es, antes que todo, derecho a espacios, tiempos y juguetes para jugar, pero también derecho a aprender a hacerlo con fantasía, en paz, sin temor a las consecuencias, ese derecho, visto así, nos crea nuevas obligaciones a los adultos vinculados con la escuela: tenemos la obligación de ponernos a estudiar cómo deben ser los patios de la escuela que queremos para la sociedad que queremos; experimentar también cómo se enseña a jugar de un modo lúdico... que no es lo mismo que discutir cómo se enseña a través del juego". (Pavía, 2010: 2)

Este mecanismo de respuesta, en función a reconocer una urgencia, trajo como consecuencia, el desplazamiento de pensar el juego como recurso, a pasar a ser incorporado el juego, a la perspectiva de derecho. En términos foucaultianos, sería esta, una función estratégica. Por lo que nos lleva a pensar, que el derecho en estos términos se presenta como un 
dispositivo de poder. Luego, el mismo se fue constituyendo legal y socialmente con el correr del tiempo. Legalmente, en el sentido de ley, es decir de la palabra escrita, de lo dicho: La Convención de los derechos de los niños, niñas y adolescentes es un ejemplo de ello.

Por su parte, los diseños curriculares han sido y son documentos donde se ve plasmado el problema de responder a una urgencia. En este caso de pasar a ser el juego un recurso, un medio para enseñar otros contenidos, para pasar a ser pensado como derecho.

"Enseñar es siempre una apuesta utópica, [...] la escuela tiene la posibilidad de constituirse en espacio de cobijo y enseñanza, reconocimiento y proyecto. El primer derecho de cada niño en la escuela es a recibir enseñanzas,

El segundo derecho de cada niño en la escuela es que crean en él, en que puede, en que tiene algo para aportar a este mundo, en que vale la pena incluirlo en los proyectos compartidos. Enseñar es reconocer al otro como sujeto capaz de aprender, de pensar, de dialogar y de producir. Ello no viene dado. No entra con la llegada de cada niño al Jardín. Es necesario advertirlo y favorecerlo". (D.C, 2008: 18)

Cuarto, un dispositivo se define por su génesis, y lo detalla en dos momentos esenciales: "un primer momento del predominio del objetivo estratégico; un segundo momento de la constitución del dispositivo propiamente dicho" (Ibid, 2004: 99). Por último, "el dispositivo, una vez constituido permanece tal en la medida en que tiene lugar un proceso de sobre determinación funcional: cada efecto, positivo o negativo, querido o no querido, entra en resonancia o contradicción con los otros y exige un reajuste"

El cuarto y quinto aspecto en la determinación de un dispositivo, se define por la constitución del dispositivo propiamente dicho y por sus consecuencias al ser determinado como tal. Pensar el juego como derecho, provocó un proceso de sobre determinación funcional, cada efecto de 
pensarlo tal cual, es un efecto positivo, querido por la sociedad en general, y en la cual entra en contradicción con los elementos de las leyes escritas, puesto que observamos que aún hay derechos que se encuentran vulnerados y por ende no garantizados por el Estado.

Pensar el derecho como dispositivo de poder, nos lleva a analizar el término "poder" a partir de Giorgio Agamben, en Homo Sacer, quien realiza una interesante diferencia entre el poder constituyente y el poder constituido. "Los poderes constituyentes existen sólo en el Estado: inseparables de un orden constitucional preestablecido, tienen necesidad de un marco estatal cuya realidad manifiestan. El poder constituido, por el contrario, se sitúa fuera del Estado; no le debe nada, existe sin él, es la fuente en la que no puede agotarse nunca el uso que se hace de su corriente. (...) De aquí la imposibilidad de construir de manera armónica la relación entre los dos poderes". (Agamben, 1998: 56).

Es por esto que, al definir el derecho como dispositivo de poder, y analizarlo como tal, encontramos elementos que no sólo se contraponen, sino que además, se yuxtaponen entre ellos mismos, lo que lleva a construir reajustes en relación al mismo.

Dejar de pensar el juego como un derecho, -puesto que implica que "ese derecho está antes de que todo empiece, en el origen del sujeto, antes de un diagnóstico, antes de un pronóstico, antes de un tratamiento o de un proyecto pedagógico" (Ibid, 2008: 19)-, y poder realizar un desplazamiento para pensarlo como una práctica, nos permite vincularlo, en nuestro campo, a una práctica en tanto corporal.

En el próximo capítulo trataremos de analizar no sólo al Juego como Práctica, sino como Práctica Corporal. A su vez, vincularemos los elementos estructurantes del juego a partir de los tres saberes propuestos por el Grupo de Investigación en Juego de la Universidad Nacional de La Plata, con el P.I.C (Programa de Investigación Científica), denominado Educación Corporal. 
Para ello tomaremos la idea de estructura propuesta por Lacan tomando el análisis realizado por Alfredo Eidelsztein ${ }^{10}$, y el trabajo realizado por Juan Bravo ${ }^{11}$ quien recurre a la teoría de los conjuntos para especificar cuáles son los elementos que estructuran a las Prácticas Corporales: Deporte y Gimnasia.

${ }^{10}$ Licenciado y Doctor en Psicología por la Universidad de Buenos Aires.

${ }^{11}$ Profesor y Licenciado en Educación Física. Magister en Educación Corporal por la Universidad Nacional de La Plata. 


\section{CAPÍTULO IV}

\section{EL JUEGO COMO PRÁCTICA CORPORAL}

En este capítulo trataremos por un lado de acercarnos hacia una definición de Juego para precisar nuestro objeto de estudio, enmarcado dentro de la teoría de la Educación Corporal, por lo que se fundamenta lógicamente en una teoría de las prácticas corporales, una teoría del sujeto, una teoría del cuerpo y una teoría de la enseñanza. Por otro lado, analizar el Juego en tanto estructura de acuerdo a aquellos elementos que permiten constituirse en una red de relaciones o covarianza entre cada uno de ellos. Siguiendo este mismo camino de pensamiento, Benveniste lo considera "como un dato de hecho, en cuanto forma, para intentar distinguir los elementos que componen la estructura". (1947:161)

Entendemos a la estructura como "...un conjunto de elementos que forman un conjunto co-variante de elementos" (Lacan, Seminario III). "Y (...) cuando nos enfrentamos a fenómenos tan complejos que no permiten su reducción a fenómenos de orden inferior, sólo podemos abordarlos estudiando sus relaciones internas, esto es, intentando comprender qué tipo de sistema original forman en conjunto." (Strauss, L.1949).

Pensar en términos de estructura significa comprenderla como un "grupo de elementos que forman un conjunto covariante que implica cierto número de coordenadas" (Lacan, 1984:160). En este sentido, ninguno de los elementos que conforman la estructura estará situado por encima de otro, no se relacionan entre sí de manera subordinada sino en términos de complementariedad y las relaciones que se presentan importan más que lo que cada uno de manera individual podría significar.

La Educación Corporal pretende una manera de pensar el sujeto y por ende de pensar el sujeto de las prácticas, el sujeto de la educación y el sujeto de la ciencia. "La Educación Corporal entiende al cuerpo y al ser humano mismo como 
constituidos en un orden simbólico" (Crisorio, 2015: 167). La Educación Corporal, la cual propone una disciplina en particular, diferente a la Educación Física, plantea como objeto de estudio las Prácticas Corporales, las cuales implican "prácticas históricas, por ende políticas que toman por objeto a las acciones del cuerpo" (2015: 170). El objeto de estudio de la Educación Corporal no es a priori, sino que se va construyendo a medida que se la va investigando; a diferencia de la Educación Física donde el objeto de estudio está dado, el cual sería en este caso, el movimiento humano. Las diferencias entre Educación Corporal y Educación Física son muchas ${ }^{12}$, puesto que pensarse en una o en otra, responde al posicionamiento en donde el enseñante pueda enfrentar la enseñanza de las prácticas de la educación del cuerpo, ya sea en la escuela, en el club o en la colonia.

\begin{abstract}
"Es preciso considerar a la Educación Física como una teoría tradicional respecto de la conceptualización del sujeto y de la educación del cuerpo, es decir, todos la conocemos, coincide con nuestro sentido común y no requiere de mayores explicaciones argumentativas. En cambio, la Educación Corporal "se presenta como una teoría moderna que opera en la novedad de lo pensado de una época, esto es, pensar de modo crítico el modo en que se viene pensando". (Lescano, 2013: 3)
\end{abstract}

Por lo tanto, "(...) el cuerpo que supone la Educación Corporal para constituirse en pensamiento y dominio de saber, es un cuerpo de la cultura, del orden significante." (Escudero, 2014: 7), o bien como lo plantea Lescano “(...) un cuerpo que se constituye en un orden simbólico no está dado o no es propiedad del hombre en tanto ser humano. El cuerpo no está instituido en el ser humano ni es un principio fundante del mismo. Entonces se puede pensar que la constitución del cuerpo no se da en su desarrollo sino en sus relaciones, en sus acciones, en sus usos, en sus actos, en sus prácticas" (2015: 98, las cursivas son nuestras). Por ende, en la Educación Corporal, se problematiza el saber como universal y el

\footnotetext{
${ }^{12}$ Para ampliar estas diferencias ver Giles, M. (2008) “Educación Corporal: algunos problemas”. Jornadas de Cuerpo y Cultura, UNLP.
} 
sujeto como particular en relación con el cuerpo de la acción, o bien en palabras de Crisorio "La educación corporal propone que el contenido es universal y el sujeto particular. En ese caso, podríamos garantizar una relación democrática con el saber. El contenido, como recorte cultural, es puesto a disposición en cada particular, sin hacer adecuaciones a priori que en el caso de la enseñanza de la educación física las más de las veces quedan regidas por características específicas como la edad, el sexo, el grupo social de referencia, etc." (2017: 145)

\section{- El Juego es una acción en tanto acto político}

De acuerdo al Diccionario Etimológico de la Lengua Española (1985: 24) la acción es: 'hecho o efecto de hacer, movimiento, actividad', del latín -ationem, acusativo de actio (radical action-) 'acción', de actus 'hecho', participio activo de agere 'hacer'.

Por su parte, la Real Academia Española, presenta 13 (trece) modos distintos de definirla; por un lado la conceptualiza desde la física que la define como "producto de la energía absorbida durante un proceso por su duración", por otro lado la explica a partir del teatro, la pintura, el cine como "sucesión de acontecimientos y peripecias que constituyen su argumento". En definitiva, se define como el "ejercicio de la posibilidad de hacer. Resultado de hacer".

Desde la perspectiva parlebasiana, "la acción en tanto motriz, es más amplia que la conducta motriz, esta última se refiere a la acción desde un punto de vista individual, es decir de las características subjetivas del individuo que actúa. La acción motriz podría referirse a un equipo o a un equipo de personas que llevan adelante una práctica corporal". (Saraví: 2015: 54). Es claro que desde esta perspectiva, nos encontramos con la especificidad de la praxiología motriz. Para analizar la acción motriz, debemos tener en cuenta: la realización material de la tarea, los mecanismos de preacción, las interacciones motrices, la red de comunicación, la decisión motriz. Si bien Parlebas se refiere tanto al individuo, a la persona y al sujeto en un mismo nivel de análisis, su posicionamiento frente a la 
idea de sujeto tiene que ver con aquel sujeto que practica, que precede a las prácticas y las realiza; en definitiva, es un individuo-persona-sujeto que no está en correlación con la teoría del sujeto que propone esta tesis, es decir un sujeto constituido en la propia práctica, un sujeto jugado.

Por último, se critica a Parlebas su intento de llevar adelante una "didáctica estructural de la Educación Física", como bien propone en su teoría de enseñanza, puesto que brinda la posibilidad de encasillar y ubicar en cuadrículas a los jugadores.

Por su parte, el antropólogo Johan Huizinga también propone el juego como una acción, pero entendida como "(...) acción u ocupación libre, que se desarrolla dentro de unos límites temporales y espaciales determinados, según reglas absolutamente obligatorias, aunque libremente aceptadas (...) acompañada de sentimientos de tensión y alegría (...) (2000: 45), por lo que al igual que la teoría parlebasiana, sostienen un sujeto jugador y no un sujeto jugado.

Pretender elaborar un concepto sobre el Juego desde la Educación Corporal, es poner en palabras una definición, la cual no pretendemos cerrar. Sabemos que al poner en palabras "algo", implica que el lenguaje es limitado, el lenguaje nos limita al definir un término. El simple hecho de utilizar el término no es neutro, pero implica, ya, un recorte de lo real, una representación del mundo.

Entendemos, entonces, desde la Educación Corporal, que el juego es una acción, acción entendida como "la única actividad que se da entre los hombres sin la mediación de cosas o materia, corresponde a la condición humana de la pluralidad (...). Mientras que todos los aspectos de la condición humana están de algún modo relacionados con la política, esta pluralidad es específicamente la condición de toda vida política" (Arendt, 2008: 23).

Desde este posicionamiento, la idea de condición no hace referencia a la naturaleza humana, es decir, -en palabras de Arendt-, "los hombre son seres condicionados, ya que todas las cosas con las que entran en contacto se convierten de inmediato en una condición de su existencia". Y acción entendida a partir de dos aspectos, por un lado como acto político, puesto que "la acción 
mantiene la más estrecha relación con la condición humana de la natalidad (...) el recién llegado posee la capacidad de empezar de nuevo, es decir de actuar. (...) ya que la acción es la actividad política por excelencia" (2008: 23).

El cuerpo no se encuentra ajeno a esta estrecha relación, el cuerpo y el sujeto se van vinculando con la práctica, se van constituyendo con la práctica misma, al igual que el discurso. Es por esto que ni el cuerpo, ni el sujeto, ni el discurso están presentes previamente a la práctica, sino que se encuentra en el entre de esa práctica en particular, en este caso en la práctica Juego. Y dentro de esa práctica corporal, siempre se actúa en una red de relaciones, donde "las consecuencias de cada acto son ilimitadas, toda acción provoca no sólo una reacción sino una reacción en cadena, todo proceso es la causa de nuevos procesos impredecibles". (Arendt, 1957: 9). Por lo tanto esa red de relaciones, no se da entre sujetos que juegan, entre jugadores, sino entre los elementos que conforman una misma estructura.

Por lo tanto, "actuar, en su sentido más general, significa tomar una iniciativa, comenzar, como lo indica la palabra griega arkhein, o poner algo en movimiento, que es el significado original del agere latino". (Ibid, 1957: 8). Cuando se usa, se pone en acto -se ejecuta- lo que se tiene disponible. Pero sólo puedo poner en acto aquello que sé. Esa puesta en acto estaría habilitada por un saber. O sea, que puedo tener la disponibilidad o puedo estar disponible para, pero no el saber para ponerla en acto. La disponibilidad quiere decir "estar disponible para", y en palabras de Mariano Giraldes es "estar disponible para actuar". O bien, la disposición a actuar corporalmente en situaciones diversas y cambiantes. En otras palabras, puedo estar disponible para, como una suerte de aptitud; pero no puedo ponerla en acto porque no tengo el saber para hacerlo por lo que

"es necesario pensar el ser-en-uso como distinto del ser-en-acto y, a la vez restituirlo a la dimensión del hábito, pero de un hábito que, en cuanto se da como uso habitual y está, por consiguiente, siempre ya 
en uso, no presupone una potencia que deba, en un determinado momento, pasar al acto." (Agamben, 2018: 121)

Por lo tanto, si asumimos que las prácticas corporales son un sistema de acción en la medida que está habitado por el pensamiento, el mismo puede y debe analizarse en todas las maneras, de hacer, decir y pensar. Es en ese sentido, que "el pensamiento es considerado como la forma misma de la acción, como la acción misma en la medida en que ella implica el juego de lo verdadero y lo falso, la aceptación o rechazo de la regla, la relación consigo mismo y con los otros (Castro, 2011: 316 en Crisorio, 2019).

Proponer que el juego es una acción en tanto acto político, nos posiciona de otra manera o desde otra mirada al momento de analizar el juego como objeto de estudio. De esta manera, nos permite poder pensar su enseñanza, en contraposición a la idea clásica de que el juego es una actividad libre, un recurso, una actividad natural que todo niño y niña trae consigo mismo, cuestión analizada en los capítulos anteriores.

Pero como todo acto en tanto político conlleva a un período histórico y cultural, es preciso pensar que el juego también es un saber cultural. Cultura en el sentido que propone Eidelzstein, la cual "implica la estructura del lenguaje y la operación significante en el seno de una sociedad de sujetos hablantes" (2001:12). O en palabras de Brougère, "Si hay una expresión del sujeto en el juego, ésta se inserta en un sistema de significaciones, o dicho de otra manera, en una cultura que le da sentido", por lo tanto al ser el Juego un saber cultural, en tanto que es valioso, transmisible y, por ende enseñable. $\mathrm{Y}$ es valioso porque nos proporciona un valor particular para su enseñanza, y es que toda práctica corporal es una acción "lujosa", y no necesaria como lo son la labor y el trabajo, lo cual permite cualificar la vida y eso ya tiene un valor que nos sirve para justificar su enseñanza. De esta manera, el juego "en términos educativos no puede ser interpretado como un bien de consumo o como un servicio, sino como una práctica lujosa, como algo que -de hecho- no tiene mayores consecuencias, ya que no es más que un juego".(Medina: 2018: 160). 


\section{- Características de las prácticas}

El Juego en tanto Práctica Corporal que toma por objeto las acciones del cuerpo, lo analizamos desde las características que Foucault le atribuye a las investigaciones acerca de ellas que nos constituyen históricamente, delimitan y definen en ¿Qué es la llustración? El filósofo plantea que toda práctica se identifica por la homogeneidad (aspectos técnicos ${ }^{13}$ y estratégicos), la sistematicidad (implican relaciones de saber, poder y ética), y la generalidad o carácter recurrente de las prácticas (según Crisorio), (determinadas por ciertas formas de problematización que definen los objetos, las reglas de acción y los modos de relación).

Una vez presentadas las características de las prácticas en general, podemos indagar sobre ¿cuáles son los elementos que convocan al conjunto Juego? Cuando hablamos de "conjunto", retomamos aquí la tesis de Bravo (2018), quien utiliza la Teoría de los Conjuntos, un modelo lógico-matemático que le permite comprender las prácticas corporales como una colección de elementos que se agrupan conformando diversos dominios con características propias.

Para ello, consideramos los saberes como elementos del juego, propuestos por el $\mathrm{GIJ}^{14}$, para analizar aquellos que conforman al conjunto Juego.

El grupo de investigación propone como condición lógica, que "permite desencadenar una situación de juego y otorga la posibilidad material del juego" (2020: 75) al distanciamiento, entendido como la acción de distanciar. "Distanciamiento es la facultad de constituir un juego. El jugar es una operación que distancia al jugador en relación con el no juego. La estructura del juego va a estar dada por este intervalo simbólico que permite que el juego exista para un jugador" (Ibid: 2020: 75), puesto que es "el juego quien determina al jugador y no al revés" (Benveniste,1947: 161) "Es él el que crea sus actores, les confiere lugar, rango, figura; reglamenta su sustento, su apariencia física, los hace incluso, según el caso, muertos o vivos" (ibid,1947: 161).

\footnotetext{
${ }^{13}$ Crisorio aclara en el texto "Prácticas Corporales en Educación Corporal", que utiliza el término técnica en el sentido que lo califica Koyré, y en términos de tecnológico como lo utiliza Foucault.

${ }^{14}$ Grupo de Investigación en Juego. Universidad Nacional de La Plata.
} 
Compartimos las ideas del GIJ, al presentar el juego como una estructura que establece una delimitación escénica.

"Esa legalidad que hace al juego como tal -o al menos al juego que intentamos signar aquí- requiere de los siguientes rasgos y saberes $^{15}$ :

1. El saber de la ficción, por lo cual aquello que se va a desplegar en el juego será un fingimiento compartido.

2. El saber que plantea el problema, donde nos enfrentamos a la situación de superar obstáculos cada vez más arduos e innecesarios,

3. El saber del acuerdo, con el que se busca la construcción y el sostenimiento del "nosotros", cuya consecuencia no es más que la de seguir jugando (aunque pueda tener consecuencias no pretendidas). $\mathrm{Si}$ alguno de estos saberes no es considerado, el juego como tal se detiene; estos saberes son patrimonio exclusivo del juego." (2020: 79)

Observamos que, para que el juego sea juego, es preciso pensar en la regla que cambia, se modifica y donde el juego se va constituyendo a partir de una interrupción, a partir de esa alteración del juego. Es en el momento de la intervención -lo cual habilita a la enseñanza, que se interrumpe también cuando "hay un cambio en la disposición de los objetos existentes, la incorporación de un material que no estaba en la escena, la realización de una acción que no ha surgido hasta el momento (...)" (Nella, 2009: 3), es decir un cambio o incorporación de la/s regla/s. De esta manera el juego va tomando forma de juego y no de otra cosa.

Sumamos al estudio realizado por Villa, M.E, Nella, J., Taladriz, C y Aldao, J., que si bien no podríamos dar cuenta del origen de los juegos, observamos que "numerosos estudios sobre el origen y la significación de la mayoría de nuestros

\footnotetext{
${ }^{15}$ Para mayor información ver "Una teoría del juego en la educación: Tras su dimensión estética, ética y política.". Villa, M.E., Nella, J., Taladriz, C., Aldao, J.
} 
juegos muestran las supervivencias, más o menos claras, de antiguas ceremonias sagradas, danzas, luchas". (Benveniste: 1947: 162), como por ejemplo -escribe Agamben- "la ronda fue en su origen un rito matrimonial; jugar con la pelota reproduce la lucha de los dioses por la posesión del sol; los juegos de azar derivan de prácticas oraculares; el trompo y el tablero de ajedrez eran instrumentos de adivinación (...). La potencia del acto sagrado reside en la conjunción entre mito que cuenta la historia y rito que la reproduce y la pone en escena". (2017: 100). Y si pensamos en una posible desacralización del juego, es decir en romper la unión entre mito y rito, podemos decir que en el juego radica uno de los dos, "como ludus, o juego de acción, deja caer el mito y conserva el ritual; como jocus, o juego de palabras, elimina el rito y deja sobrevivir el mito" (ibid: 100). Por lo tanto, en el campo de las prácticas corporales, es el rito que emerge con mayor énfasis en el juego, puesto que "llamamos acción, o acciones, al modo en que el cuerpo se involucra en estas prácticas; de modo que no es un cuerpo de las prácticas sino un cuerpo de la acción, que en sí mismo no es más que sus acciones" (Crisorio, 2019: 20), y es desde allí que pretendemos analizar el juego en tanto saber a enseñar. $\mathrm{Si}$, en caso contrario, analizamos la propuesta del mito como jocus o juego de palabras, sólo podríamos pensar el juego desde otro campo, por ejemplo en el campo de la recreación, puesto que desde esa perspectiva, se podrían incluir cualquier tipo de juego además del juego corporal. Por lo tanto, se trata aquí de plantear que el juego es una práctica corporal y la misma tiene por objetos las acciones del cuerpo, y esas acciones se definen como respuestas particulares no estereotipadas para los requerimientos de una determinada práctica.

En síntesis, el problema que se presenta aquí entre mito y rito es que, si ambas se encuentran presentes, estaríamos frente a una ceremonia sagrada, y si dejamos caer el mito por sobre el rito, tendríamos sólo un juego de palabras.

Por otro lado, pensamos que el juego enseña a profanar puesto que "restituir el juego a su vocación puramente profana es una tarea política", como propone Agamben (2005: 101). "Profanar significa abrir la posibilidad de una forma especial de negligencia, que ignora la separación o, sobre todo, hace de ella un uso particular" (Ibid, 2005: 99). En el juego observamos momentos de profanación 
durante el tiempo que transcurre, ya que no significa sólo abolir y eliminar las separaciones -del mundo real-, sino aprender a hacer de ellas un nuevo uso armando otra dimensión del mundo también real-. Si profanar implica emanciparse de una situación en el juego y hacer un uso distinto de esa situación o una nueva dimensión de ese uso, en el juego en tanto corporal implica un hecho profanatorio. Por lo tanto, enseñar juego es, también, enseñar a profanar.

En definitiva, es pensar el juego desde su estructura y no a partir del jugador, ni de los jugadores, ni del contexto. Analizar la enseñanza del juego desde esta perspectiva, nos permite organizar estratégicamente el saber a enseñar. Por lo tanto, cada uno de estos rasgos o saberes son elementos que estructuran al juego en tanto práctica corporal, donde los mismos, "toman valor unos de otros y al mismo tiempo se lo otorgan entre sí" (Bravo, 2018: 57). Y al proponer la enseñanza de un juego, se plantea desde la lógica del mismo, en donde entran en acción de modo covariante y sin distinción jerárquica entre cada uno de ellos. 


\section{CONCLUSIONES}

En principio, la propuesta de esta tesis no tiene como propósito la búsqueda de la verdad, más bien se trata de precisar el objeto de estudio, el cual en este caso ese objeto de estudio se encuentra dirigido a tensionar no sólo los conceptos de derecho y de derecho al juego, sino también, cómo esos posicionamientos han ido marcando el rumbo de leyes, documentos, proyectos y escritos en el ámbito de la educación en general y en la educación del juego en particular, vinculados especialmente a la naturaleza del hombre.

Luego de haber realizado un recorrido por los cuatro capítulos de la tesis, observamos que en primera instancia el título de la misma ya nos provoca a un juego de palabras: "El sujeto con derecho a jugar: entre el juego como derecho y el derecho al juego". En cada uno de los capítulos se van problematizando, no sólo a partir de la historicidad del término derecho, sino también a partir de su genealogía. Como consecuencia, se plantea un análisis en relación a la modificación de la fórmula: juego como derecho - derecho al juego. Y si hablamos de derecho, hablamos de sujetos quienes supuestamente hacen uso de esos derechos.

En cualquiera de las posibles definiciones que le han proclamado al derecho de los sujetos, a pesar de los grandes esfuerzos realizados por organizaciones y pensamientos en pos de brindar ciertos derechos, -en este caso al juego- se continúa una línea de pensamiento donde el derecho se mantiene como sustancial, natural y esencial. 
La tesis realiza un recorrido entre individuo portador de derechos - sujeto de derechos, lo cual lleva a pensar al juego como derecho - derecho como sujeto derecho como sujeto jugado - finalizando con el juego como práctica corporal.

Querer proponer cierta tensión al concepto de derecho, no sólo desde su genealogía sino también desde los momentos históricos donde han ido emergiendo las diversas propuestas de derechos en tanto humanos, nos permite analizar por qué hoy se encuentra posicionado al derecho y por ende el derecho al juego, a partir de una mirada totalmente sustancial del mismo. A su vez, se plasma en la tesis, específicamente en el capítulo IV, la idea de pensar al derecho como dispositivo de poder. Este análisis nos permite continuar en el camino de corrernos en pensar al juego como derecho y pensarlo como práctica en tanto corporal.

Esta tesis realiza un análisis sobre cada uno de ellos, en la cual pudimos demostrar que el derecho es un concepto esencial, natural, necesario y vital; o en palabras de Seré "el derecho se funda en la naturaleza humana y no en las condiciones sociales, políticas, económicas o históricas". Esta posición sustancialista, responde a una visión de sujeto, es decir, un sujeto que es precedido por la práctica y que, como consecuencia, también el derecho al jugar se ve plasmado desde esta misma mirada.

Este trabajo pudo, entonces, realizar una crítica y análisis del derecho en general y del derecho al jugar en particular, y proponer otra perspectiva en vinculación al derecho y al juego a partir de la teoría de la Educación Corporal, teoría en que se apoya esta tesis. En la misma, no hay naturaleza humana ni derecho alojado en lo natural, más bien hay sujetos que se van constituyendo a partir de lo que representa para otro significante; es decir el juego se va constituyendo a partir de lo que los sujetos jugados van armando en ese constructo llamado Juego. 
Por su parte, la Convención sobre los Derechos del Niño es un tratado internacional de las Naciones Unidas, firmado en 1989, a través del cual se enfatiza que los niños tienen los mismos derechos que los adultos, y se subrayan aquellos derechos que se desprenden de su especial condición de seres humanos que, por no haber alcanzado el pleno desarrollo físico y mental, requieren de protección especial. (C.N.D)

Si bien es sabido que existen documentos, convenciones y organizaciones internacionales en vinculación al derecho al juego y al jugar, no es nuestro propósito criticar estos documentos y escritos, que mucho esfuerzo han realizado para que se cumplan y garanticen los derechos en especial a los niños, niñas y adolescentes del mundo. Más bien, analizamos la epistemología que subyacen sobre el derecho provenientes de pensamientos epocales que fueron transmitidos de una manera u otra, hasta llegar a nuestros días donde el derecho emana como una propuesta sustancial, esencial y natural de la humanidad. Esta posición epistemológica en torno al derecho, nos provoca a presentar otra perspectiva sobre la misma, la cual se encuentra vinculada al pensamiento sobre el Juego como Práctica Corporal a partir de la teoría de la Educación Corporal. Y desde allí, poder plantear su enseñanza en el ámbito de la educación del cuerpo.

En el seno de las prácticas educativas, estos sentidos parecieran replicarse puesto que la influencia de ciertos enunciados vertidos desde la psicología, también con sentidos vitalistas - biologicistas, han instalado en la lógica que hace funcionar las prácticas que refieren al juego y al jugar del niño, una racionalidad que ha establecido un modo de pensarlos, de decirlos, de hacerlos, en fin, de practicarlos.

En definitiva esta maniobra con el derecho al juego dentro del ámbito escolar pretende "mostrar el cuerpo totalmente impregnado de historia, y la historia impregnando al cuerpo" (Foucault, 2004: 32). 
El Programa de Investigación Científica, propuesto por Imre Lakatos consiste en una sucesión de teorías relacionadas entre sí, de manera que unas se generan partiendo de las anteriores. Estas teorías que están dentro de un PIC comparten un núcleo firme o duro. El núcleo firme está protegido por un cinturón protector que consiste en un conjunto de hipótesis auxiliares que pueden ser modificadas, eliminadas o reemplazadas por otras nuevas.

En nuestro caso, el P.I.C. se denomina Educación Corporal, lo cual propone un cinturón protector a partir de teorías que son articulables y lógicas entre sí. Entre ellos se encuentra una teoría del sujeto, una teoría del cuerpo, una teoría de las prácticas corporales -donde uno de los saberes es el Juego como así también, el Deporte, la Gimnasia, las Prácticas en la Naturaleza y la Danza-, y una teoría de la enseñanza.

Para pensar esta última, partimos de que el Juego es forma en sí misma, y como dijo Benveniste "el juego determina al jugador" y no al revés.

Si bien planteamos que el Juego es una acción en tanto acto político, puesto que existe una red de relaciones entre cada uno de los elementos que lo constituyen; también existen cuestiones políticas vinculadas a la enseñanza, como por ejemplo la selección de saberes a enseñar, como por ejemplo los modos de intervención durante esa práctica, como por ejemplo pensar la enseñanza en términos de problemática. Cada uno de ellos se encuentran vinculados políticamente al momento de enseñar un saber en este caso: el Juego.

La problematización en términos de enseñanza nos habilita, según Foucault, a la elaboración de un dominio de hechos, de prácticas y de pensamientos. "Pensamiento es lo que permite tomar distancia a una manera de hacer o reaccionar, dársela como objeto de pensamiento e interrogarla sobre su 
sentido, sus condiciones y sus fines. El pensamiento es la libertad con respecto a lo que se hace, el movimiento mediante el cual nos desprendemos de ello, lo constituimos como objeto y lo reflejamos como problema". (1984) La problematización responde a dificultades u obstáculos de una práctica, en este caso la práctica Juego, y propone posibles transformaciones con diversas soluciones prácticas. A su vez, "elabora las condiciones en las que se pueden dar respuestas posibles, define los elementos que constituirán lo que las diferentes soluciones se esfuerzan en responder". (Idib)

Para ello, es preciso realizar una intervención, una interrupción en esa práctica en particular, para que la problematización se visibilice en la posibilidad de poder dar respuestas posibles a ese o esos problemas que la práctica demande. 


\section{BIBLIOGRAFÍA UTILIZADA}

- Agamben, G. (2005). El hombre sin contenido. Editorial Altera, Madrid.

juego de niños, Buenos Aires, Las Cuarenta.

(2018) El uso de los cuerpos, capítulo 6: El uso habitual. Adriana Hidalgo editora. Buenos Aires.

- Arendt, H. (2008). La condición humana, Editorial Paidós. Buenos Aires.

- Benveniste, E. (1947). "Le jeu comme sctructure", Deucalion 2. París. Traducción de Eduardo Villegas Mejías.

- Brougére, G. (2013). El niño y la cultura lúdica. En Lúdicamente Año 2 $\mathrm{N}^{\circ} 4$, Octubre.

- Castro, E. (2004). El vocabulario de Michel Foucault. Un recorrido alfabético por sus temas, conceptos y autores, Universidad de Quilmes: Bernal.

- Crisorio, R. (2015) en Diccionario crítico de la educación física académica, Editorial Prometeo Libros. Buenos Aires.

y Escudero, C. (coord.) (2017). Educación del cuerpo. Curriculum, sujeto y saber. FaHCE, UNLP.

---------(2018) Prácticas Corporales en Educación Corporal. CICES/IdIHCS-UNLP/CONICET. Argentina

-------(2019) Programa de Investigación en Educación Corporal. Universidad Nacional de La Plata.

- Degano, J. (2006). El derecho a ser niño, Memorias de las XIII Jornadas de Investigación y Segundo Encuentro de Investigadores en Psicología 
de Mercosur "Paradigmas, Métodos y Técnicas", Tomo II, Facultad de Psicología UBA. Buenos Aires.

- Devís, J. \& Sánchez, R. (1996). La enseñanza alternativa de los juegos deportivos: antecedentes, modelos actuales de iniciación y reflexiones finales. En Moreno, J.A. \& Rodríguez, P.L. (comps.).Aprendizaje deportivo. Murcia: Universidad de Murcia.

- Diccionario Jurídico argentino. (2004). Buenos Aires.

- DGCyE, (2008) Diseño Curricular de Educación Física para la Educación Inicial, Resolución 3161/07. Buenos Aires.

(2008) Diseño Curricular para la Educación Primaria. Primer Ciclo Volúmen 1 / Dir. General de Cultura y Educación de la Provincia de Buenos Aires.

- -----------(2009) Diseño Curricular para la Formación Docente en Educación Física. Provincia de Buenos Aires.

- --------- (2019) Diseño Curricular para la Educación Inicial. Dir. General de Cultura y Educación de la Provincia de Buenos Aires.

- Elías, N. (1995), "Demasiado tarde o demasiado pronto" en Mi trayectoria intelectual. Barcelona, Península.

- ---------(2012). $3^{\circ}$ edición. El proceso de la civilización. Investigaciones sociogenéticas y psicogenéticas. Fondo de Cultura Económica. México, D.F.

- Esposito, R. (2007) Tercera persona Política de la vida y filosofía de lo impersonal. Amorrortu editores Buenos Aires - Madrid.

- Fernández, L. (1989). Derecho natural y poder político. Diferencias entre Spinoza y Hobbes. ISSN Impreso: 0120-0062.

- Foucault, M. (1982/1983). El gobierno de sí y de los otros: curso en el Collége de France. Fondo de Cultura Económica de Argentina. S.A. 
- --------(1984) Estética, Ética y Hermenéutica. Editores:

Barcelona : Paidós.

--------- (1990). Vigilar y castigar. Nacimiento de la prisión. Ed. Siglo XXI. Buenos Aires, Argentina.

--..- (2002). ¿Qué es la llustración?, en Filosofía de la historia, México. Fondo de Cultura Económica.

- --------(2007) La arqueología del saber. Siglo XXI Editores Buenos Aires, Argentina.

- Fröebel, F. (2003) La educación del hombre. Traducida del alemán por Don J. Abelardo Núñez. Edición anotada por W. N. Hailmann. Biblioteca virtual Universal.

- Gómez de Silva, (1998) Diccionario etimológico de la lengua española. Fondo de Cultura Económica. México.

- Lacan, J. (1964). Seminario XV. Problemas cruciales para el psicoanálisis. Inédito.

- -------------(2007) Mi Enseñanza. Editorial Paidós. Buenos AiresBarcelona-México.

- Le Breton, D. (1995) Antropología del cuerpo y de la modernidad. Cap. 2. Ediciones Nueva visión. Buenos Aires.

- Lescano, A. (2013) Educación Corporal: el saber como sujeto. Inédito.

- ------(2015) Lo que el sujeto es y no es. ¿El sujeto es mensurable en el cuerpo? CICES (Centro Interdisciplinario, Cuerpo, Educación, Sociedad) IdIHCS-CONICET, FaHCE-UNLP.

- Medina, J. (2018). Reflexiones sobre la tecnología disciplinar en la práctica deportiva. Tesis de posgrado. Universidad Nacional de La Plata. Facultad de Humanidades y Ciencias de la Educación. En Memoria 
Académica.

Disponible

en:

http://www.memoria.fahce.unlp.edu.ar/tesis/te.1621/te.1621.pdf

- Mendel, G. (1973). "Acerca de la regresión de lo político al plano de lo psíquico- Sobre un concepto sociopsicoanalítico" en Sociopsicoanálisis I, Buenos Aires, Amorrortu.

- Neef, M.N. (1994) Desarrollo a escala humana: Conceptos, aplicaciones $y$ algunas reflexiones. Editorial Nordan - Comunidad, Montevideo, Uruguay.

- Pavía, V (1995) Investigación y juego : Reflexiones desde una práctica. Revista: Educación Física y Ciencia 1995. Editor: Universidad Nacional de La Plata. Facultad de Humanidades y Ciencias de la Educación. Departamento de Educación Física.

(2009). Cuerpo, Juego y Cultura, Congreso Pedagógico AMSAFE, Santa Fé. -(2009). Formas del juego y modos de jugar. Fundación Arcor.

-------(2010) EFDeportes.com, Revista Digital. Buenos Aires, Año 15, № 149,. http://www.efdeportes.com/

- Revista digital para profesionales de la enseñanza №17. Federación de Enseñanza de CC.OO de Andalucía. Noviembre 2011.

- Rivero, I. (2020) Revista digital Educación Física y Ciencia, abril-junio 2020, vol. 22, n² , e123. ISSN 2314-2561. Universidad Nacional de La Plata. Facultad de Humanidades y Ciencias de la Educación. Departamento de Educación Física. Hechos que posicionaron el juego como objeto de estudio. Rastreo a partir de producciones bibliográficas.

- Stenhouse, L. (1991). Investigación y desarrollo del curriculum, Morata, Madrid. 
- Schmitt, C. (1932). El concepto de lo político, Editorial Rutgers University Press. Traducido por Rafael de Agapito Serrano. (2006) Teoría de la constitución. Ed. Alianza. Madrid.

- Taladriz, C.- Nella; J,- Aldao, J. y Villa, M.E (2011). Una genealogía del juego en la historia de la Educación Física escolar. Proyecto de investigación: "La enseñanza del juego en la Educación Física", perteneciente al Programa de Incentivos a la Investigación, FAHCE, UNLP.

(2020) Una teoría del juego en la educación: Tras su dimensión estética, ética y política, La Plata: Universida Nacional de La Plata. Facultad de Humanidades y Ciencias de la Educación.(Estudios-Investigaciones; 72). En Memoria Académica. Disponible en: http://www.memoria.fahce.unlp.edu.ar/libros/pm.1189/pm.1189.pdf: 